\title{
External Support to Schools on Probation: Getting a Leg Up?
}

Kara Finnigan

Jennifer O'Day

Follow this and additional works at: https://repository.upenn.edu/cpre_researchreports

Part of the Curriculum and Instruction Commons, Educational Administration and Supervision Commons, Educational Assessment, Evaluation, and Research Commons, and the Education Policy Commons

\section{Recommended Citation}

Finnigan, Kara and O'Day, Jennifer. (2003). External Support to Schools on Probation: Getting a Leg Up?. CPRE Research Reports.

Retrieved from https://repository.upenn.edu/cpre_researchreports/36

by Kara Finnigan and Jennifer O'Day with assistance from David Wakelyn.

View on the CPRE website.

This paper is posted at ScholarlyCommons. https://repository.upenn.edu/cpre_researchreports/36

For more information, please contact repository@pobox.upenn.edu. 


\title{
External Support to Schools on Probation: Getting a Leg Up?
}

\author{
Abstract \\ In 1996, the Chicago Public Schools (CPS) began implementing a new school accountability policy \\ designed to improve student performance by providing a combination of consequences and support to \\ low-performing schools. The center point of the accountability system, the Chicago school probation \\ policy, designates schools as being "on probation" if fewer than $15 \%$ (later raised to $20 \%$ ) of their students \\ score at grade-level norms on the lowa Test of Basic Skills in reading. When placed on probation, schools \\ face the consequences of decreased autonomy and the threat of more severe sanctions. At the same \\ time, probation schools receive direct assistance from several different sources through the policy's \\ external support system. The purpose of the support is to assist schools in strengthening their internal \\ operations, raising expectations for students, and improving instruction so as to foster increased student \\ achievement. \\ This report is based on a two-year study of the design and implementation of the school probation policy \\ in Chicago's elementary schools. The school accountability system in Chicago has undergone changes \\ since the end of this study as a result of new district leadership. The system now includes the use of \\ additional assessment data and subject area tests, emphasis on progress and growth, and a focus on all \\ schools. In spite of these changes, the assistance provided by probation managers and external partners \\ has not changed. Therefore, the lessons learned from this study should still be relevant not only to CPS \\ but also to other jurisdictions instituting similar policies.

\section{Disciplines} \\ Curriculum and Instruction | Educational Administration and Supervision | Educational Assessment, \\ Evaluation, and Research | Education Policy

\section{Comments} \\ by Kara Finnigan and Jennifer O'Day with assistance from David Wakelyn. \\ View on the CPRE website.
}




\title{
External Support to Schools on Probation: Getting a Leg Up?
}

\author{
Kara Finnigan \\ Jennifer O'Day
}

with the assistance of David Wakelyn

July 2003 



\section{Table of Contents}

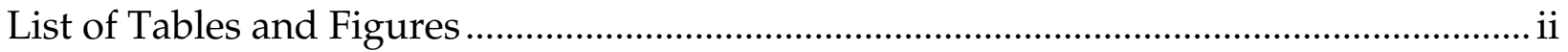

Acknowledgments and Authors' Note ...........................................................................ii

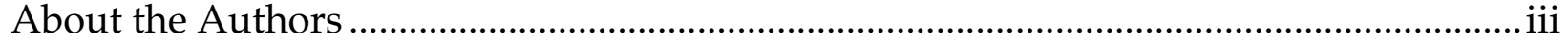

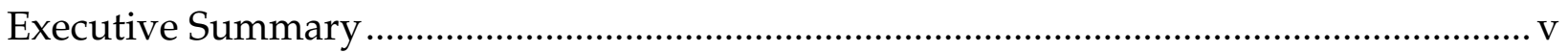

Overview of External Support to Probation Schools .................................................... v

Provider Strategies and Implementation of Assistance ................................................vi

Implementation Constraints..................................................................................... vi

Strength of External Support and Implications .........................................................vii

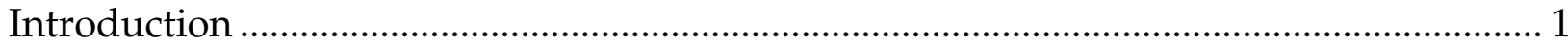

Overview of External Support to Probation Schools ........................................................ 3

Support as an Integral Aspect of the Probation Policy................................................ 3

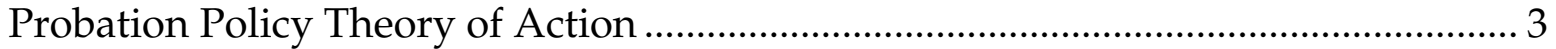

The Design of External Support........................................................................... 5

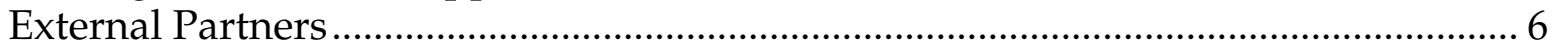

Probation Managers.............................................................................................. 7

Conceptualizing Support: Analytic Frames and Methodology ...................................... 11

Policy Implementation: The Mediating Role of Change Agents ................................ 11

Provider Theories of Action: Capacity, Intervention, and Professional Learning ....... 13

Instructional Capacity ................................................................................... 13

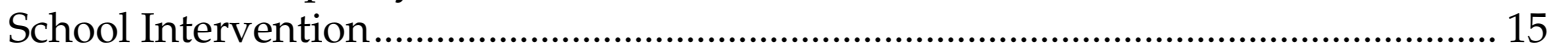

Opportunities for Professional Learning ............................................................ 16

Provider Strategies and Implementation of Assistance .............................................. 19

Overview of Assistance............................................................................................. 19

Construction of the Problem and Goals of Support Providers .................................... 20

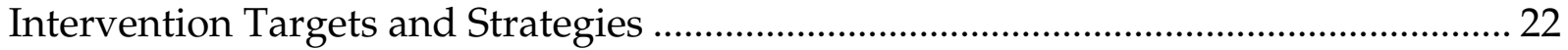

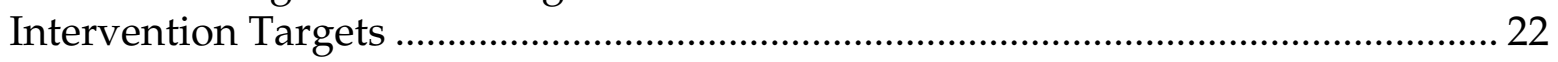

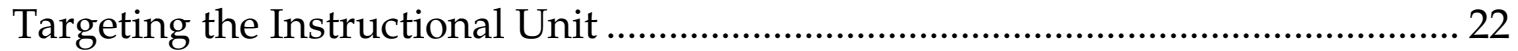

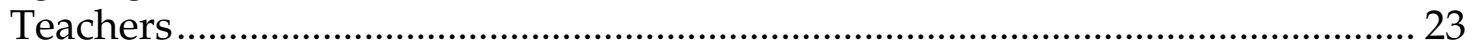

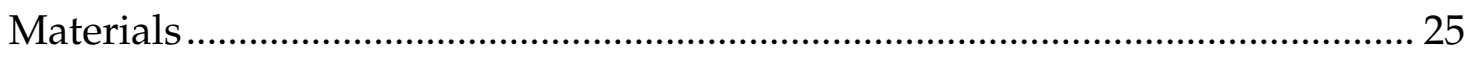

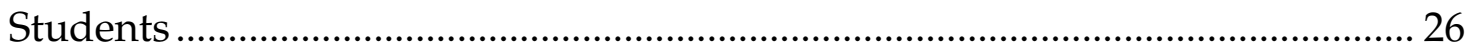

Interaction among Teachers, Students, and Materials .................................... 27

Targeting the Instructional Environment: Building Organizational Capacity ..... 27

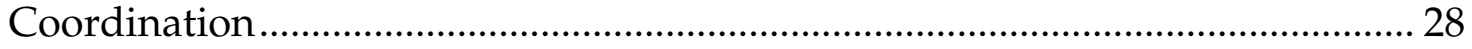

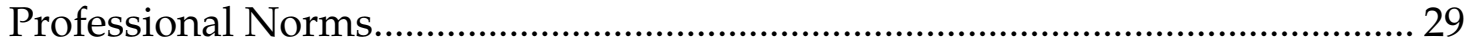

Resources for Learning and Instruction ...................................................... 30

Monitoring of Instruction and Student Learning ........................................... 31

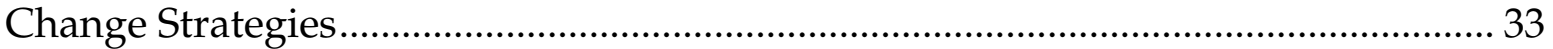

Opportunities for Adult Learning: Methods and Content of Professional

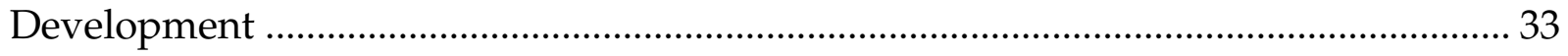

Implementation Constraints of External Assistance ................................................. 36

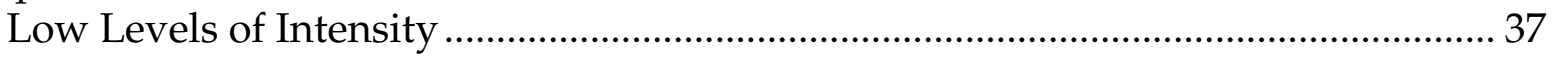

Lack of Communication among Providers ........................................................ 39 
Uneven Targeting of Literacy Instruction ......................................................... 39

Lack of Clear Strategies for Organizational Change ................................................ 40

Reliance on Traditional Professional Development Strategies ................................ 40

Strength of External Support and Implications ..................................................... 43

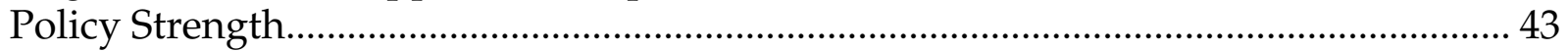

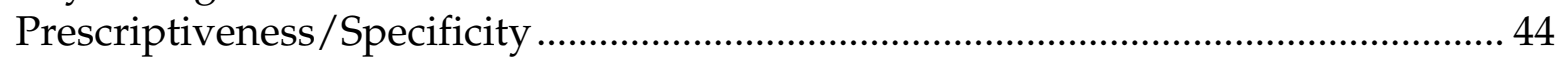

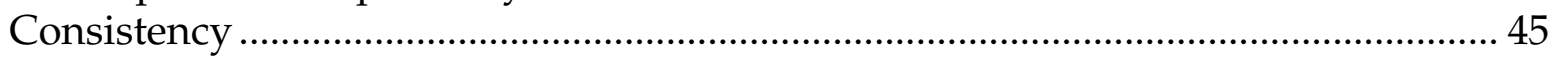

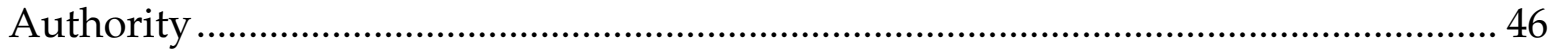

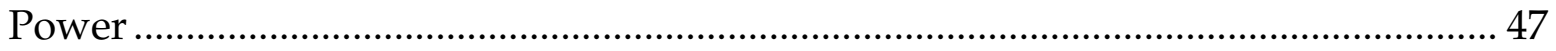

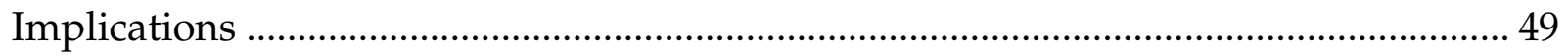

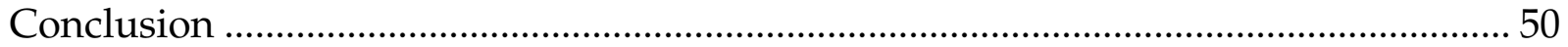

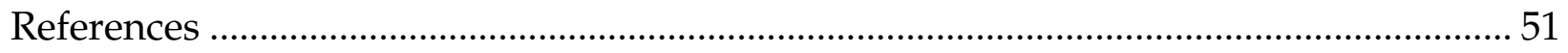

Appendix A. Description of External Partners Participating in Study ............................ 55

\section{List of Tables and Figures}

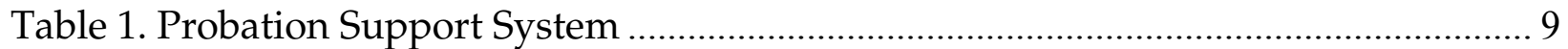

Figure 1. Simplified Theory of Action Underlying CPS Probation Policy ......................... 5

Figure 2. The Design of External Support ................................................................ 5

Figure 3. Implementation Framework ..................................................................... 12

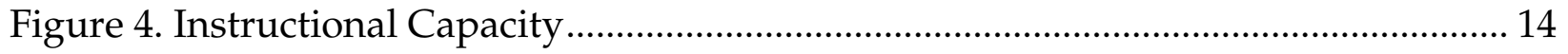

Figure 5. Overlapping Targets of Intervention........................................................... 23 


\section{Acknowledgments and Authors' Note}

Research for this report was supported by the John D. and Catherine T. MacArthur Foundation, the Spencer Foundation, and the United States Department of Education's Institute of Education Sciences (formerly the Office of Educational Research and Improvement). In addition to David Wakelyn, the authors would like to thank John Easton, Langston Evans, Betheny Gross, Julia Gwynne, Rodney Harris, and Helen Wei for their assistance in data collection and analysis. The authors also extend their deep appreciation to the Chicago Public Schools staff, as well as the external partners, probation managers, and school staff, who took time out of their busy schedules to discuss the probation policies and their work. Finally, the authors thank the Consortium on Chicago School Research for providing office space and additional resources as well as colleagueship and collaboration in this effort.

This report reflects the interpretation of its authors, and does not necessarily reflect the views of the John F. and Catherine T. MacArthur Foundation, the Spencer Foundation, the United States Department of Education, the Institute of Education Sciences, the Consortium on Chicago School Research, or the Consortium for Policy Research in Education and its institutional members. Although the Consortium on Chicago School Research assisted in the development of this research, no formal endorsement by its Steering
Committee members, their organizations, or the Consortium on Chicago School Research should be assumed.

\section{About the Authors}

Kara Finnigan is an educational research consultant and doctoral student at the University of WisconsinMadison. Her expertise is in the areas of educational policy and school reform with a focus on urban schools. Her dissertation examines the relationship between principal leadership and teacher expectancy in schools on probation. She is also focusing on charter school accountability and the role of authorizers through a study funded by the United States Department of Education.

Jennifer O'Day is a Principal Research Scientist and policy analyst in the American Institutes for Research's (AIR) education program. Before joining AIR, she was Assistant Professor of Educational Policy Studies at the University of Wisconsin-Madison, a senior researcher with the Consortium for Policy Research in Education, and Associate Director of the Pew Forum on Standards-based Reform. Much of her recent research has centered on school improvement, capacity building, and accountability in standards-based reform. 
David Wakelyn is a senior associate at the National Center on Education and the Economy in Washington, DC. He assists America's Choice schools and districts in understanding federal and state policy. He earned an M.A. in Public Policy from the La Follette Institute at the University of Wisconsin and a B.A. in American History from Vanderbilt University. 


\section{Executive Summary}

In 1996, the Chicago Public Schools (CPS) began implementing a new school accountability policy designed to improve student performance by providing a combination of consequences and support to lowperforming schools. The center point of the accountability system, the Chicago school probation policy, designates schools as being "on probation" if fewer than $15 \%$ (later raised to $20 \%$ ) of their students score at grade-level norms on the Iowa Test of Basic Skills in reading. When placed on probation, schools face the consequences of decreased autonomy and the threat of more severe sanctions. At the same time, probation schools receive direct assistance from several different sources through the policy's external support system. The purpose of the support is to assist schools in strengthening their internal operations, raising expectations for students, and improving instruction so as to foster increased student achievement.

This report is based on a two-year study of the design and implementation of the school probation policy in Chicago's elementary schools. The school accountability system in Chicago has undergone changes since the end of this study as a result of new district leadership. The system now includes the use of additional assessment data and subject area tests, emphasis on progress and growth, and a focus on all schools. In spite of these changes, the assistance provided by probation managers and external partners has not changed. Therefore, the lessons learned from this study should still be relevant not only to CPS but also to other jurisdictions instituting similar policies.

\section{Overview of External Support to Probation Schools}

The Chicago school probation policy's external support system includes five school-level support providers: an external partner, a probation manager, a regional education officer, a business manager or intern, and a facilitator from CPS's Office of Accountability. For this study, we focused on the role of the two external agents - the external partners and probation managers - because they are the central components of the system. Schools select their external partners, which tend to be either universities or individual consultants, but the seasoned administrators known as probation managers are assigned to one or two schools by the district. Although neither role is specified in great detail, external partners tend to provide professional development and work with staff on aspects of school improvement, while probation managers mentor and supervise the principal and oversee the implementation of the school's improvement planning process.

Several characteristics of Chicago's design of external assistance are noteworthy. Support is a prominent feature of the probation policy recognizing the need for capacity building in low-performing schools, CPS spent approximately $\$ 29$ million on this effort between 1997 and 2001. The 
policy emphasizes the provision of sitebased assistance in order to improve the school as an educational unit. Instead of generic professional development activities, teachers receive professional development as part of a school-wide improvement plan, and most of the assistance occurs on site. The policy includes multiple avenues of support and the separation of the probation manager and external partner roles. Most of the policy's external assistance - that of the external partners - is market based, allowing for a better "fit" between their needs and the external partner's program because they select and contract with these independent providers. A final aspect of the policy is a relative lack of emphasis on training of support providers and the absence of built-in mechanisms for learning, either on the part of the providers or the district.

\section{Provider Strategies and Implementation of Assistance}

External partners and probation managers locate the problem of low performance within the schools - either at the classroom or organizational level. However, beyond pointing out the internal nature of the problem, support providers vary in their description of its source or solution. When targeting individual (classroom) capacity, external partners primarily focus on teachers, but most partners also provide some type of materials, from assessments to lesson plans. While most partners target the development of teachers' knowledge and skills, few emphasize content knowledge and learning. Most professional development takes the form of traditional half-day or full-day workshops with more limited attention to one-on-one assistance and modeling in classrooms. To the extent that external partners focus on the environment or organization to build capacity, their interventions frequently overlap with those of probation managers. The organizational-level efforts of both groups targeted one or more of four areas: coordination and leadership, professional norms for teachers and teaching, the monitoring of instruction and student learning, and resources for learning and instruction.

\section{Implementation Constraints}

Our evidence clearly points to the fact that all probation schools receive assistance from a probation manager and external partner. The variation we observe in these providers' strategies is consistent with the market-based approach, and most respondents report general satisfaction with the support system.

However, our analysis suggests several problem areas that we believe limit the impact of this support.

- Low levels of intensity. While varying among providers, the intensity of assistance delivered to probation schools is, we believe, simply inadequate to address the substantial needs of the individuals and organizations concerned. Some partners attempted to extend the reach beyond the time that the consultants were in the schools through train-the-trainer approaches and on-site literacy coordinator 
models. Our observations in case study schools suggest that professional development in the train-the-trainer model was much too weak to extend into other teachers' practices, while the on-site literacy coordinators hold more promise.

- Lack of communication among providers. According to our respondents, the lines of communication generally flowed from central office personnel to providers with little opportunity for feedback or for open communication and collective problem-solving among external partners, among probation managers, or between partners and probation managers. We saw similar communication problems mirrored in our case study schools.

- Uneven targeting of literacy instruction. One rather surprising finding was that most support providers implement strategies that only weakly attempt to improve literacy. Only 4 of the 11 partners included in this study had developed a comprehensive, research-based approach to literacy instruction.

- Lack of clear strategies for organizational change. While the goal of the assistance was to develop capacity and alter practices throughout the school unit, support providers generally lacked a comprehensive intervention or dissemination strategy based on an articulated theory of action or understanding of organizational change.

- Reliance on traditional staff development models. Most partners continued to rely on traditional forms of staff development primarily short-term workshops with little intensive assistance to teachers, little examination of student work, and few ongoing opportunities for cross-grade, crossclass, and cross-school collaborative learning.

\section{Strength of External Support and Implications}

Through its allocation of substantial resources and attention to the external assistance efforts, CPS has demonstrated not only a recognition of the need for capacity building in its low-performing schools but also a commitment to its realization. Few jurisdictions have, from the outset, designed an accountability system with this level of commitment to school assistance. Moreover, the incorporation of multiple layers of assistance reflects the district's recognition of the variability in school contexts, focus on the "fit" between the providers and the schools, and attempt to involve the broad education community, including institutions of higher education, in improvement efforts.

Unfortunately, despite the millions of dollars put into assistance, we conclude that the support component of the probation policy is simply too weak to make it through the many layers of implementation to significantly alter 
classroom instruction. We find the assistance system to be under-specified with respect to the target and goal of the assistance, to lack clear authority or incentives to encourage participation, to suffer from inconsistencies and even conflicts with other policies, and to be of generally too low intensity to induce the kinds of learning and change needed at the level of classroom instruction.

Based on our analysis, we suggest seven implications for policy:

1. Constrain the market choice, both with respect to direction and in terms of quality. We believe the provision of assistance would be improved if the number of partners were limited to a handful of proven groups that were required to offer or support a coherent and comprehensive instructional program at least in the area of literacy. In this more constrained market approach, the district could better ensure both quality and appropriate variation and flexibility, assisting low-capacity schools to make more useful choices.

2. Clarify roles of support providers. The existence of multiple partners and providers almost guarantees fragmentation at the school level. We suggest that the roles of probation managers, regional education office staff, and Office of Accountability facilitators be consolidated into a single and clear line of authority in the schools and that this authority work closely with the external partner to help schools develop and implement a coherent instructional program.

3. Develop opportunities for learning/sharing among partners and probation managers. We strongly urge the district to design professional development for these support providers and opportunities for them to reflect collectively on their work, its effects, and resulting lessons.

4. Discourage schools from developing multiple and fragmented partnerships by giving the external partner the authority to coordinate assistance from all external sources while the school is on probation.

5. Stimulate the development of indepth, content-based professional development. An example of such staff development might be the twoweek session on reading instruction for Targeted Assistance Program teachers held in the fall of 2000. Despite the implementation problems of short notice and inconsistency with some literacy programs, this effort to foster deeper content and pedagogical content knowledge in literacy was an important step and should be pursued further.

6. Connect assistance to the standards, not just the test. We observed a real problem of teaching to the test in several of our case study schools, a problem that is exacerbated by the lack of attention to the standards and the reliance on a single indicator for 
both student promotion and school probation. As long as the Iowa Test of Basic Skills is the sole indicator and everything rides on it, it will become the de facto standards of the district.

7. Promote better use of data in schools by fostering the development and implementation of multiple diagnostic tools such as running records, periodic curriculum-based assessments, and examination of more extensive examples of student work. 


\section{Introduction}

In 1996, the Chicago Public Schools (CPS) made history by placing 109 of its lowest performing schools on academic probation through its accountability policy known as the Chicago school probation policy. The goal, simply, was to shake up the system and improve student performance. Of the schools put on notice, 71 were elementary schools ${ }^{1}$ and 38 were high schools. Although the magnitude of the CPS action was unique (a full one-fifth of its schools were placed on probation), the underlying CPS policy mirrors educational accountability systems instituted in many states and urban districts in recent years.

A hallmark of Chicago's policy is the combination of consequences and support. This combination is meant to improve student performance by increasing both the will and the capacity of educators to teach well. The consequences of probation include a decrease in autonomy while the school is on probation and the threat of more severe sanctions (reconstitution or reengineering) should student achievement not improve in a reasonable period of time. ${ }^{2}$ The support

\footnotetext{
${ }^{1}$ Most elementary schools in Chicago include kindergarten through eighth grade.

${ }^{2}$ Reconstitution refers to the removal of staff. Re-engineering, CPS's subsequent incarnation of reconstitution, consists of a year-long assessment period during which the district decides whether to hire and fire staff. Each school is given $\$ 500,000$ in resources during the assessment period. No elementary schools had been targeted for reconstitution or reengineering at the time of this study.
}

component employs multiple groups and individuals within and outside the district to provide assistance to probation schools.

This report focuses on the provision of external assistance to probation schools. Our examination of this component is based on a two-year, multi-level study of the design and implementation of the school probation policy in Chicago's elementary schools. Following this introduction, we provide an overview of the role and system-level design of external assistance. We then outline the analytic frames and data sources that informed this investigation. Next, we describe the design and implementation of assistance at the support provider level. We conclude with a discussion of the overall strength of the support system and implications for policy and practice. 


\section{Study Methods and Data}

This report is based on data from multiple sources from July 1999 through February 2001. The study team began by interviewing administrators in CPS's Office of Accountability to better understand the origin and evolution of the school probation policy. This report is primarily based on the interviews and observations of 11 of the 18 external partners providing support to schools during this time period. We interviewed both external partner directors and consultants and shadowed a subset of five partners serving the bulk of probation schools. The partners participating in this study are listed in Appendix A along with the number of schools associated with each at the time.

This report is also based on interviews with a random sample of 16 (of the 53) probation managers who were working with at least one probation school at the time of data collection. These interviews focused on the ways in which probation managers monitored school performance and assisted principals with school management and leadership. Other data sources for this report include interviews with four Office of Accountability facilitators who worked with approximately 30 probation schools, reviews of district documents relating to school probation and the system of external support, and observations of support provider meetings and workshops when possible.

To better understand the school-level perspective, we interviewed a random sample of 15 principals at probation or post-probation elementary schools about their experiences with external partners and probation managers and their satisfaction with the support provided through this policy. In addition, this report draws on interviews and observations at the 10 schools involved in our case study analysis. It is important to note that describing the system of external support is a difficult task because it has been a moving target. On the one hand, the district has changed its policies over time. On the other hand, turnover in district staff, external partners, and probation managers proved challenging to this study. 


\section{Overview of External Support to Probation Schools}

\section{Support as an Integral Aspect of the Probation Policy}

Although this report focuses almost exclusively on the policy's system of external support for elementary schools, it is important to understand how this component fits within the overall policy design. This section provides a brief overview of the design, assumptions, and theory of action of school probation in Chicago.

Low performance has plagued Chicago schools for many years and has inspired multiple critiques and policy responses. The most recent of these responses - direct school accountability for student performance - is a result of the convergence of both local and national factors. Locally, a shift in the city and state political contexts in the early 1990s gave the mayor and his newly appointed Chief Executive Officer (CEO) greater authority to intervene in troubled schools. ${ }^{3}$ At the same time, the national political landscape was also shifting toward higher standards, more rigorous assessments, and increased accountability for student learning. Consistent with this larger political landscape, CPS began tightening control over its schools, defining accountability in terms of student test scores, and placing schools with the lowest student

\footnotetext{
${ }^{3}$ See Bennett (2001) for a detailed account of the political context of this policy.
}

performance on probation until that performance improved. ${ }^{4}$ While the probation policy appeared negative (largely because of the term "probation" and the stigma associated with it), the district described it as a "positive step," emphasizing a shift to the needs of students and the provision of support to low-performing schools (Chicago Public Schools, 2000b).

\section{Probation Policy Theory of Action}

District administrators interviewed for this study attributed low performance in probation schools to several factors: poor principal leadership, inadequate instructional knowledge and low expectations on the part of teachers, and lack of motivation for improvement. ${ }^{5}$ School probation represents a central district response to these problems. As such, the school probation policy rests on a set of underlying assumptions common to recent accountability approaches. These assumptions taken together make up a general "theory of action" (Argyris \& Schon, 1978), the broad components of which are as follows:

\section{- The accountability system should} be aligned with educational goals. If increased student achievement is the goal, then student achievement is what educators should be account-

\footnotetext{
${ }^{4}$ Authority for the probation policy derives from a 1995 revision of Illinois legislation on Chicago school reform.

${ }^{5}$ Preliminary interviews were conducted in spring 1997, shortly after the first schools went on probation. Subsequent interviews of district personnel occurred from March 1998 through spring 2001.
} 
able for and what the system should monitor. The belief is that the accountability system will draw attention to the desired goals and focus effort on their achievement. In Chicago, these goals are measured primarily through the Iowa Test of Basic Skills (ITBS).

- The school should be the basic unit of accountability. Two beliefs support the school as the unit of accountability. One is that student performance is cumulative and influenced by the entire school program and climate. A second is that a system of collective (schoolbased) accountability will encourage educators at the school to work together, thus increasing overall capacity and performance.

- The threat of negative sanctions will motivate educators to work harder, thus improving student achievement. The underlying belief here is that persistently low student performance stems primarily from educators' lack of will. Negative sanctions are to provide the extra push for school personnel to do what is necessary to raise student achievement.

- Accountability measures should be accompanied by capacity building. CPS administrators recognize that limited capacity (knowledge, skills, and resources) at the school also contributes to low performance. By providing assistance from outside the school, CPS administrators hope to create the capacity needed to improve instruction and student learning.

- Goal setting, planning, and monitoring results are critical to improvement. The underlying belief is that very broadly defined goals do little to focus attention, suggest strategies, or provide feedback for improvement. Schools need specific, measurable goals and well-specified plans for achieving them. In Chicago, this process is incorporated into the annual School Improvement Plan for Advancing Academic Achievement, required of all schools, and the reading plan, required of probation schools.

As illustrated in Figure 1, the implicit theory of action is that threat (or consequences), combined with support, will increase educator motivation and capacity to improve performance. ${ }^{6}$ Improved educator performance will, in turn, lead to increased student achievement, the ultimate goal of the policy. As is evident, assistance to schools is an integral part of the theory of action behind probation - it is this assistance that will enable the improvement policymakers seek.

\footnotetext{
${ }^{6}$ Unlike many other jurisdictions at the time, CPS also recognized in the mid-1990s the importance of attending to student motivation and capacity and chose to address these issues through the student promotion and retention policy and through provision of additional learning opportunities in summer and afterschool programs. See Roderick, Bryk, Jacob, and Easton (1999) for research on grade promotion and retention practices and results.
} 
Figure 1. Simplified Theory of Action Underlying CPS Probation Policy

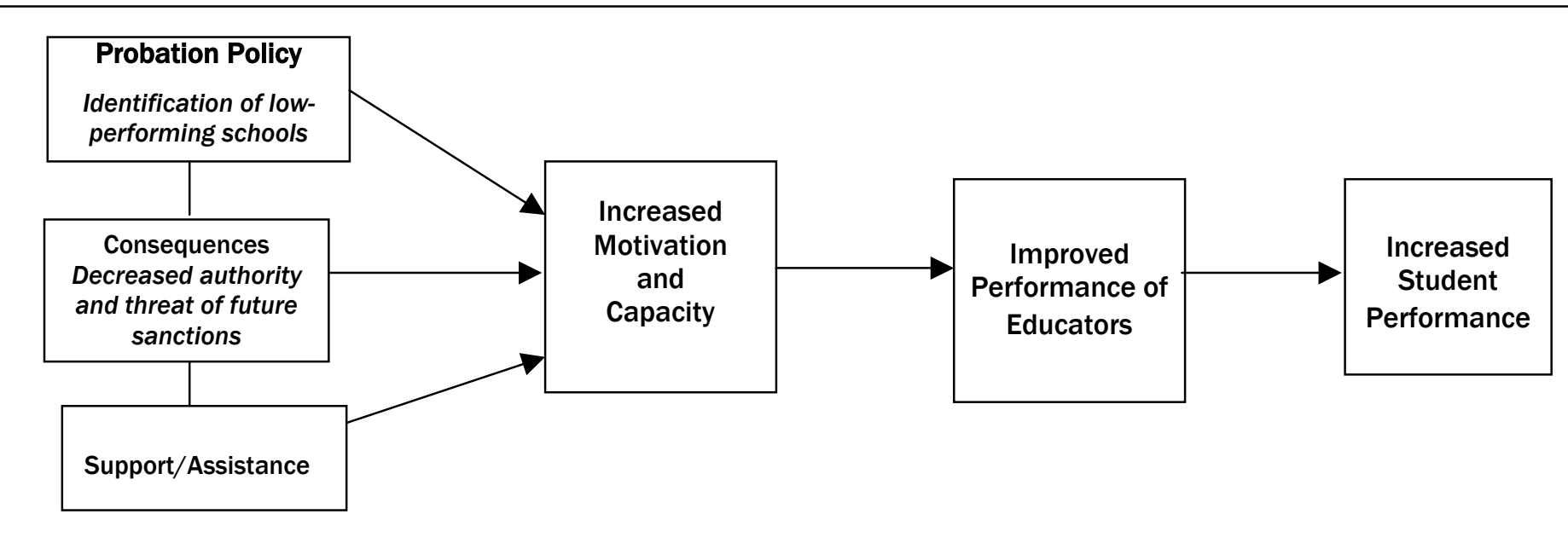

\section{The Design of External Support}

The district's external support system, described by CPS as "targeted support," was designed with one objective in mind: to improve student achievement as measured by standardized tests (Chicago Public Schools, 1999). The system includes five school-level support providers: an external partner, a probation manager, a regional education officer, a business manager or intern, and a facilitator from CPS's Office of Accountability. Figure 2 illustrates the multi-faceted system of external support. For this study, we focused on the role of the two external agents - the external partners and probation managers - because they are the central components of the support system.

Figure 2. The Design of External Support

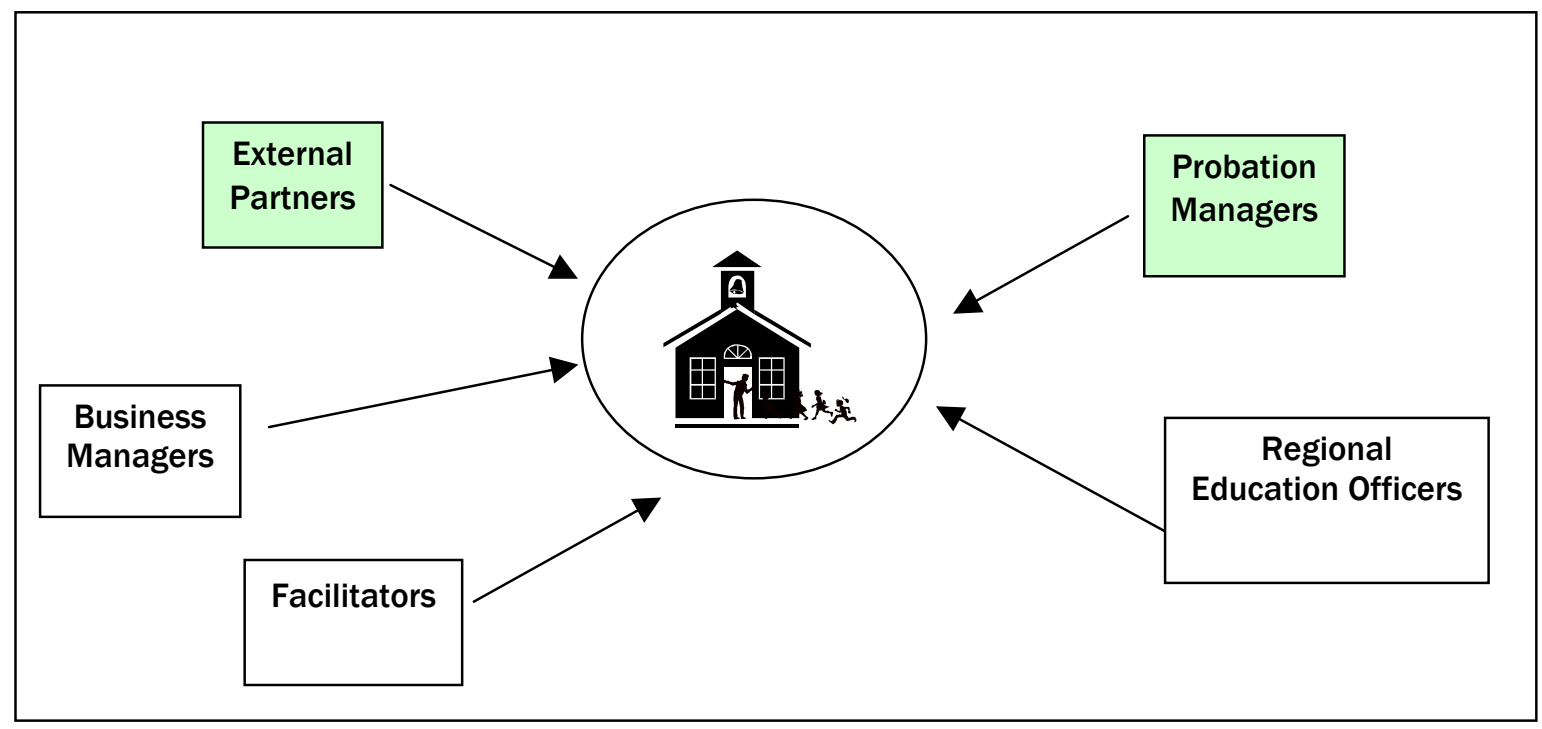




\section{External Partners}

The most intensive provision of support to probation schools is through the external partners. According to district administrators, the strategy for the external partners was intended to combine district resources with a commitment from external agencies particularly institutions of higher education - through annual contracts with each school (see sidebar below for other models of external assistance to low-performing schools). To be approved as an external partner, a college, university, or educational organization must submit a three-page proposal stating its "program" or approach. Although the district does not require that every external partner address each area, the RFP (Request for Proposals) emphasizes the following goals for the partners' work:

1. Increase student achievement, particularly in reading and math as measured on standardized tests;

2. Improve school leadership, including school organization and fiscal management;

3. Establish a student-centered learning environment;

4. Provide effective professional development opportunities; and

5. Promote parent/community partnerships.

\section{Models of External Assistance}

Chicago's model of devolving authority to the school site to choose an (approved) assistance provider that is external to both the school and the system is but one approach to supporting capacity building in low-performing schools. Other jurisdictions have chosen to bring expertise to low-capacity schools through differing combinations of external and internal assistance. In Kentucky, for example, the state education agency established a core of "distinguished educators," successful teachers and administrators, throughout the state who were selected, trained, and paid by the state education agency to work for two years with the principal and staffs of "schools in decline" (Kentucky's equivalent of probation). These distinguished educators were individuals external to the low-performing school but internal to the state education system. In Baltimore, by contrast, district leaders have contracted with Achievement First - a program of the local education fund - to provide comprehensive, literacy-based professional development and school intervention to lowperforming (reconstitution-eligible) schools in the CEO district. In this case, the agent is external to the system but contracted by the district (rather than the schools themselves) to provide a specific program of intervention and capacity building to a group of targeted schools. San Diego employs yet another model with district-trained literacy coordinators as full-time staff in schools and peer coaches/staff developers to work with literacy coordinators and principals. In this case, assistance is internal to the school and the larger system, and it is multi-layered to incorporate learning among coordinators and other assistance providers. 
"After completing and submitting a proposal, each partner is selected based on its ability to raise student performance and its ability to customize the assistance to meet the individual needs of each school" (Chicago Public Schools, 1999). ${ }^{7}$ Once approved, the partner's name appears on a list of candidates from which probation schools may choose. At any one time, approximately 16-18 groups have been authorized as external partners. Although the central office assigned partners to some schools during the first year of probation, by the time of this study, the choice had been entirely delegated to the schools themselves. One rationale for this flexible, marketbased approach to assistance was reportedly to allow for a better "fit" between the needs and philosophy of the school and the approach of the service provider.

Since the inception of the policy, the district and the schools have shared funding for the partner's services in a graduated approach. The first year of a school's partnership with an external partner is fully funded by the Office of Accountability. In the second year, the school must assume one-half the cost of the partnership, and in the third year (and thereafter) the school is responsible for the full amount. In addition, after a school is removed from probation (regardless of the point in this threeyear process), it must continue its relationship with a partner for one full

\footnotetext{
${ }^{7}$ The criteria used to determine whether the prospective partner can accomplish those tasks, however, remains unspecified in any district publication.
}

year so that the supports to the school are not withdrawn immediately. ${ }^{8}$ External partners must provide CPS with invoices, logs, and other materials to document their assistance.

\section{Probation Managers}

The Office of Accountability also assigns a probation manager to each school on probation. According to Phil Hansen, former director of the Office of Accountability, "they are our eyes and ears" at the school site. ${ }^{9}$ Probation managers must be seasoned administrators - a current principal, a retired principal, or a district administrator - with proven success as a building leader. The assumption here is that success in their own schools or districts has provided these administrators with the expert knowledge needed to guide or advise the principal of the low-performing school. Half of the probation managers who participated in our study were former principals who had also served in other positions at the district and university level (e.g., central office staff, university faculty, or superintendents of neighboring districts). Most of the others were current principals. As of May 2000, the responsibilities of the probation manager (listed in district documents) included monitoring the School Improvement Plan for Advancing Academic Achievement and

\footnotetext{
${ }^{8}$ Since 1999, many probation schools have been able to garner additional federal resources to support their work with external partners through the Comprehensive School Reform Demonstration program.

${ }^{9}$ Interview, March 27, 1997.
} 
the school's financial situation, leading the probation management team, ${ }^{10}$ and mentoring the principal.

Before probation managers begin working with their schools, the Office of Accountability provides them with general information about probation, as well as the reporting requirements of this position. No formal training for the position has been required or provided, however. At the time of this study, each probation manager received a stipend of $\$ 5,000$ for every school they assisted. In recent years, CPS limited the maximum number of schools for probation managers. For example, probation managers in our study commonly worked with one school each, although a few assisted two. In the early years, a few probation managers assisted as many as four or five schools at a time.

As shown in Figure 2, three other individuals work with probation schools as part of the support system. The school business manager or intern is responsible for business activities (such as ordering instructional materials and assisting with the budget), thus freeing the principal to focus on instructional tasks. A person from the regional education office serves as a liaison between the school and the Office of Accountability, while one or more Office of Accountability administrators assess the school through site visits and

\footnotetext{
${ }^{10}$ The manager leads a team at each probation school that includes the partner, current principal, local school council representative, school business manager or intern (at discretion of the principal), and regional education office representative. This team is required to meet monthly.
}

operate as "facilitators" between the support providers and the schools.

The focus of this study is the role of the primary assistance providers, the external partners and probation managers. These groups work with individual schools but, by design, have differing roles and targets. External partners are expected to provide professional development and work with staff on aspects of school improvement, including the school planning process. Probation managers mentor and supervise the principal and oversee the implementation of the School Improvement Plan for Advancing Academic Achievement. In the first few years of the policy, CPS permitted these two groups to function under one roof; that is, external partners could also be probation managers. CPS no longer allows partners and managers to serve a dual role because it reportedly received complaints about the services provided. In doing so, the district also began asking probation managers to monitor the external partners informally. As illustrated in Table 1, further delineation has occurred over time, although there continues to be overlapping responsibilities in many probation schools.

Reliance on external assistance for probation schools developed in response to two considerations: the limited capacity of the central office to provide support to nearly one-fifth of CPS's schools and the district's interest in engaging outside groups, especially universities, in school improvement in Chicago. The district sought to strengthen relationships with 
Table 1. Probation Support System

\begin{tabular}{|c|c|}
\hline Support Provider & Role \\
\hline External Support Partner & $\begin{array}{l}\text { - Educational organization that assists schools in the improvement of } \\
\text { student achievement. } \\
\text { - Works with school staff on appropriate issues. } \\
\text { - Assists in ensuring good school/community relations. }\end{array}$ \\
\hline Probation Manager & $\begin{array}{l}\text { - High-level school administrator with principalship experience. } \\
\text { - Oversees implementation of modified school improvement plan. } \\
\text { - } \quad \text { Monitors school educational progress. }\end{array}$ \\
\hline $\begin{array}{l}\text { School Operations } \\
\text { Manager/School } \\
\text { Business Manager Intern }\end{array}$ & $\begin{array}{l}\text { - Experienced business executive for high schools; interns for most } \\
\text { elementary schools. } \\
\text { - Manages operational and financial aspects of the school. } \\
\text { - Frees principal to focus on educational leadership of the school. }\end{array}$ \\
\hline Regional Education Office & $\begin{array}{l}\text { - Resource link between schools and Central Service Center. } \\
\text { - Helps to ensure smooth day-to-day operations and provides technical } \\
\text { assistance where needed. }\end{array}$ \\
\hline Office of Accountability & - Oversees and acts as liaison to schools and to support system. \\
\hline
\end{tabular}

Source: Chicago Public Schools, 2000a

institutions of higher education, in particular, in the belief that this would have a positive long-term effect on teacher training. According to district administrators, the involvement of these external groups would help institutions of higher education to better understand the challenges and problems facing lowperforming schools and thus enable them to more appropriately prepare prospective teachers to work in these settings.
In the next two sections, we delve more deeply into the nature of the assistance provided by the probation managers and external partners. Our goal is to describe the variation in support and to suggest possible lessons for the district and others from this rich experiment in assisting low-performing schools. First, we lay out the analytic frame and methodology we bring to this exercise, and then describe the work of the providers, using this frame. 


\section{Summary: Design Features of CPS Support to Probation Schools}

Several characteristics of Chicago's design of external assistance stand out from this discussion.

- First is the prominence of the support component of the probation policy. Recognizing the need for capacity building in low-performing schools, CPS has spent millions of dollars on this effort. ${ }^{11}$

- Second is the emphasis on providing site-based assistance in order to improve the school as an educational unit. Generic, individually based, off-site professional development activities for teachers play little role in the probation policy; rather, teachers receive their professional development as part of a school-wide improvement plan, and most of the assistance occurs on site with colleagues.

- Third is the establishment of multiple avenues of support and the separation of the probation manager and external partner roles; the former is geared more toward monitoring and principal support and the latter toward instructional assistance for teachers.

- Fourth, the bulk of the external assistance - that of the external partners - is market based. Schools select and contract with independent providers. That selection is only moderately constrained by the proposal process - directions to partners are very general, and multiple approaches and targets are acceptable on the assumption that this flexibility will better meet the needs and contexts of individual schools. In addition, monitoring of partners from the central office is relatively light as quality and fit are to be controlled in large part by the ability of the school to switch partners if unsatisfied. ${ }^{12}$ Such switching is facilitated by the fact that most partners are based in the Chicago area.

- A final aspect of the design worth noting is the relative lack of emphasis on training of support providers (e.g., probation managers are selected based on their track records and receive little or no additional training in mentoring other school leaders) and the absence of built-in mechanisms for learning, either on the part of the providers or the district. Partners and probation managers report that monthly meetings are mainly for communication from the district to the providers, with few avenues for systematically sharing practices or lessons from the field. While this is hardly unique to Chicago, the failure to take advantage of the natural variation engendered by the market approach may impede improvement of the system over time.

\footnotetext{
${ }^{11}$ This approximate figure includes federal Comprehensive School Reform Demonstration program grants, which now provide a major source of funding for the external partners.

${ }^{12}$ Indeed, approximately $50 \%$ of schools on probation have switched partners at least once. Generally, schools initiated the change, but occasionally the partner did so. In either case, a lack of fit is generally reported to be the primary explanation, though in some cases, according to the schools in our study, partners simply did not follow through on promises made at the time the contract was negotiated. In addition, a portion of the switching appears to have resulted from partners "going out of the business" of providing support to low-performing schools.
} 


\section{Conceptualizing Support: Analytic Frames and Methodology}

In this section, we draw on several lines of research to outline the analytic frames for this study. Our discussion begins with lessons from the expansive literature on policy implementation, noting in particular the critical mediating role played by agents in the intermediate layers of the system, like the assistance providers. We then turn to the strategies of the providers themselves, using literature on instructional capacity, school intervention, and professional development to suggest important components of the providers' work.

\section{Policy Implementation: The Mediating Role of Change Agents}

McLaughlin (1987) argues that policymakers cannot directly change schools because implementation at the local level depends on individual as well as external factors. Whatever its original design, a policy is transformed as agents at multiple levels of the system interpret, adapt, and act on it (Elmore, 1987; Spillane, 2000; Weatherly \& Lipsky, 1977). This interpretation and adaptation are based on two factors: beliefs of individuals and the contexts in which those individuals work (McLaughlin, 1987; Spillane, 2000). Beliefs include implicit and explicit assumptions about goals, problems and their causes, and viable points of intervention. Contexts include such things as capacity at both the individual and organizational levels. Variation in beliefs and contexts leads to variation in implementation.

In the case of Chicago school probation, the expected variation in implementation is likely to be exacerbated - even encouraged - by reliance on an only moderated, constrained marketplace of support providers. External partners, and even probation managers, bring to the schools differing assumptions and strategies - or, in the words of Argyris and Schon (1978), differing theories of action. Moreover, because these providers are the ones who work most closely with school personnel, their theories of action play a crucial mediating role for the probation policy. The picture is further complicated when one considers that there are multiple probation support providers for any one school (see Figure 2) and even partners and vendors outside the probation system. This raises the question of whether the theories of action of the assistance providers are consistent with one another and with those of the district administration. Hatch (1998) found that differences in the theories of action of different school reform organizations and individuals may inhibit change. A central concern behind our investigation of the support system in Chicago was to understand these differences and their potential impact on improvement efforts.

The implementation literature also underscores the importance of considering implementation issues at several levels of the system - in this 
Figure 3. Implementation Framework

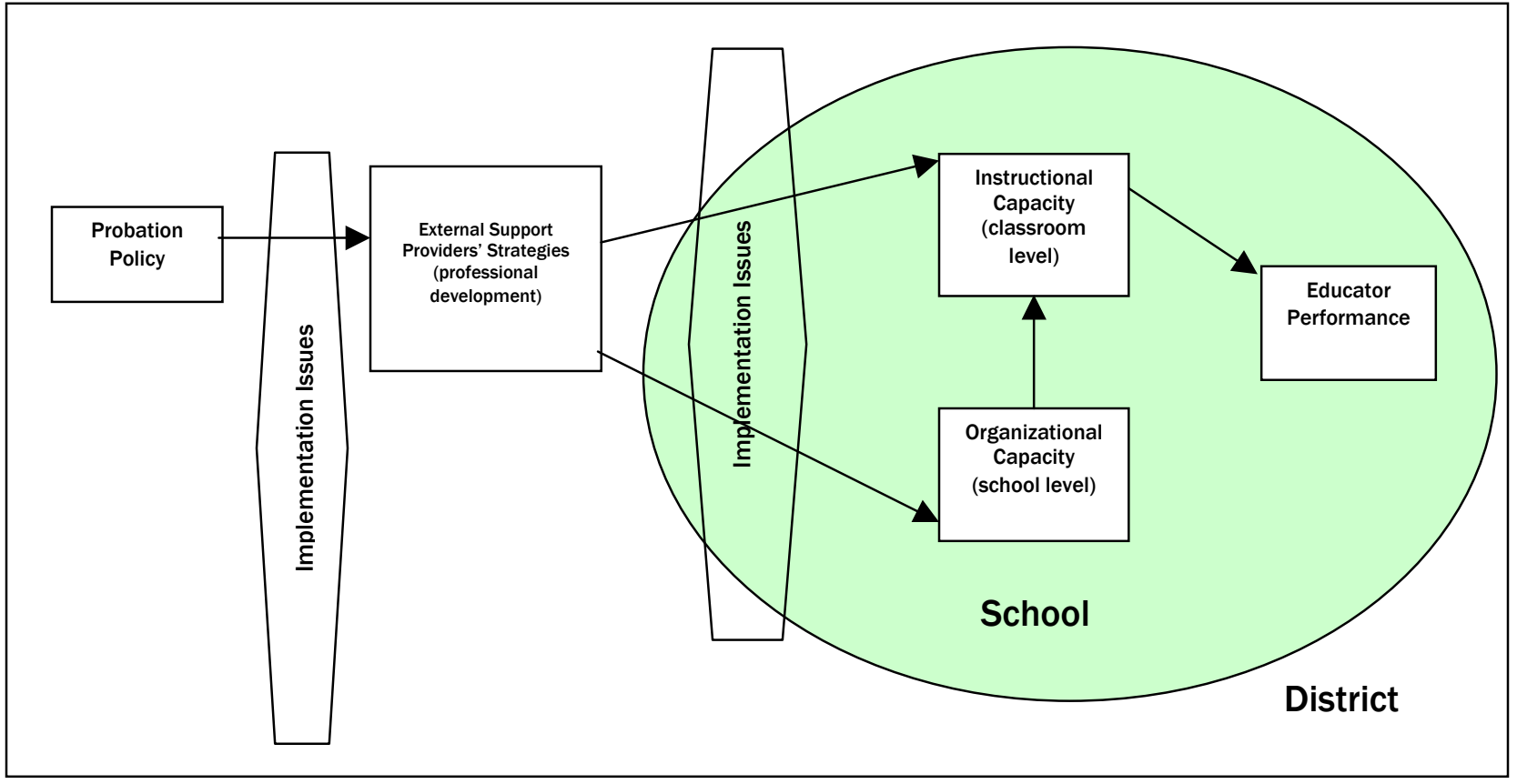

Note: This framework shows the linkages between the policy and educator performance. However, the policy's ultimate goal is to change student performance and the route to bringing about this change is through educator performance.

case, between the district and the providers, among the providers themselves and between them and the schools, and within the schools (as teachers and administrators interact with the interveners). This report focuses primarily on the design and implementation of support at the policy and provider levels with additional supporting data from our case studies. Figure 3 portrays this multi-level implementation frame for the external support component of this policy. Both individual actors and the policy context affect policy implementation as support providers and school staff interpret and respond to the policy. An important component of this framework is represented by the circle (school) nested within the rectangle (district) - illustrating that the policy targets teachers and building administrators but that these individuals are nested within larger competing contexts. Figure 3 also illustrates how the external providers assist the school by targeting the two levels of capacity: instructional capacity in classrooms and organizational capacity of the school unit. Below, we consider literature that guided our analysis of the targets and forms of assistance support providers pursued in their efforts to build instructional capacity. 


\section{Provider Theories of Action: Capacity, Intervention, and Professional Learning}

As discussed above, providers' theories of action and strategies for capacity building play crucial roles in the implementation and ultimate success of the school probation policy. A central task of this report is to describe the variation in those strategies. A variety of literature helps flesh out the components of providers' theories of action. First, we consider the literature on instructional capacity, on the dual assumption that the goal of most support providers is to increase the capacity of schools to improve student learning, and understanding how providers conceptualize that goal is critical for understanding their strategies to reach it. We then turn to the literature on external assistance and intervention as a basis for understanding providers' intervention strategies. And, finally, we consider research on professional development, a major component of the providers' work.

\section{Instructional Capacity}

Schools are nested systems of individuals operating within organizations. Therefore, two levels of capacity are important to highperforming schools - individual capacity and school capacity.

Goertz, Floden, and O'Day (1995) identify four dimensions of individual teacher capacity: knowledge, skills, dispositions, and views of self. Much of the literature has focused on the first two dimensions, teacher knowledge and skills. In the mid-1980s, Shulman (1986) posited that three types of instructional knowledge are central to teachers' work: knowledge of content (e.g., mathematics), pedagogical content knowledge (e.g., how children learn mathematics), and general pedagogical knowledge. This delineation was significant in its emphasis on the centrality of instructional content in teaching, a break from earlier "process product" research that focused primarily on generic pedagogical techniques. Since that time, many researchers have explored the role of content knowledge and pedagogical content beliefs on teachers' work and student learning (e.g., Fennema \& Carpenter, 1992). They have also extended the discussion of necessary knowledge to include knowledge of students and of instructional context. ${ }^{13}$

Individual educator capacity is not enough to ensure student learning, of course. Beginning with the effective schools research and continuing through literature on organizational learning and complexity, analysts have also focused on the organizational aspects of capacity (Levine \& Lezotte, 1990; Mohrman \& Lawler, 1996; Newmann \& Wehlage, 1995; O'Day, Goertz, \& Floden, 1995; Purkey \& Smith, 1983). Much of this literature has examined the characteristics of highperforming schools on the assumption that these are characteristics that should

\footnotetext{
${ }^{13}$ Shulman (1987), himself, noted that teachers need other kinds of knowledge including knowledge of the curriculum, students, educational contexts, and educational ends.
} 
Figure 4. Instructional Capacity

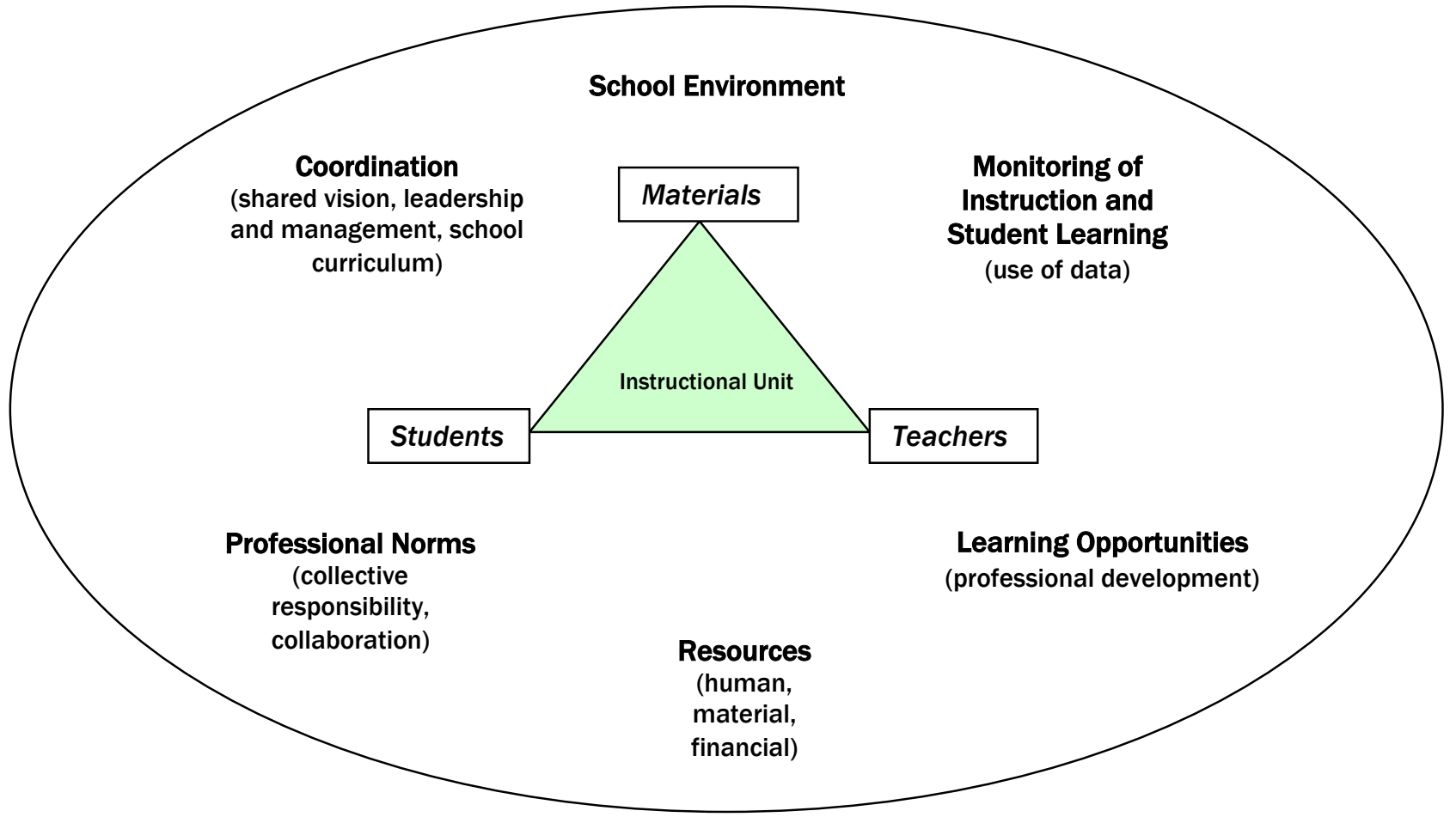

be promoted in less successful ones. These characteristics included such things as a shared vision focused on student learning and common strategies for engendering that learning, a culture of professional collaboration and collective responsibility, high-quality curriculum and systematic monitoring of student learning, strong instructional leadership (usually from the principal), and adequate resources. More recent research has especially noted the importance of professional community (McLaughlin \& Talbert, 1993; Newmann \& Wehlage, 1995) in which information and authority are shared (DarlingHammond, 1996; Mohrman \& Lawler, 1996).

Cohen and Ball (1999) have brought together and further complicated the two levels of capacity. They argue that, at its base, instructional capacity is "a function of the interaction among [teachers, students, and educational materials], not the sole province of any single one, such as teachers' knowledge or skill, or curriculum." Moreover, because the instructional unit (teachersstudents-materials) is nested within the organization, interaction with and management of the environment is integral to understanding instructional capacity. Relevant aspects of the instructional environment are the level of instructional coordination among classrooms and individuals, opportunities for professional and organizational learning, the prevailing normative structures in the school, the ways in which teaching and learning are monitored and incentives provided for improvement, and the level and type of resources available. Figure 4 portrays Cohen and Ball's conception of instructional capacity, to which we have 
added elements from the literature on organizational capacity. This conceptualization forms the basis for much of our examination of providers' theories of action.

\section{School Intervention}

While educational researchers may be able to delineate the characteristics of successful, high-capacity individuals, units, and schools, much less is known about effective intervention strategies for developing capacity and improving instruction. Indeed, one of the major criticisms of the effective schools movement was that it assumed a direct link between specified characteristics of effective organizations and a strategy for change.

Interestingly, despite the millions of dollars spent on external change agents in school reform (and business restructuring), research on their effectiveness remains sparse. Researchers like Huberman (1995) note the importance of bringing new information and outside perspectives into school communities, but investigations like the RAND Change Agent Study (Berman \& McLaughlin, 1978) find little impact of external change agents, in part because of problems of fit between the school and the provider and failure of providers to adjust their programs to the contexts of individual schools. A decade later, this finding was modified based on more flexible agent-school relationships (McLaughlin, 1987), and several other studies have found that school "coaches" can play an important role in developing the capacity of schools
(O’Day, Goertz, \& Floden, 1995), even those identified as low performing (David, Kannapel, \& McDiarmid, 2000). But what is the nature of effective intervention for improving instruction? What are its targets and what are its forms?

Because schools are complex organizations, finding effective leverage points, or targets, of intervention is far from straightforward. Interactions among the multiple actors in a school setting as well as influences from outside make causal attributions in the change process difficult (Axelrod \& Cohen, 1999). Cohen and Ball (1999) point out that interveners differ markedly in their targets - some focus on students, others on teachers, and others on curriculum and instructional materials. Still others seek primarily to alter the environment in which instruction takes place by restructuring the school organization or adding resources. These researchers suggest that a change in teachers has greater potential because teachers play a mediating role in instruction. They also argue that interventions that target the interaction of the three elements of the instructional unit may have the greatest effect.

Whether or not external support providers can or will effectively influence instructional interaction in the classroom, however, is in some doubt. Some past research has found that external partners are most helpful at the school (organizational) level, rather than the teacher level, because the external partners are unable to give the intense assistance to teachers necessary to help 
them develop skills within their own classrooms (Cox, 1983). Similarly, others point out that support providers generally spend inadequate time in the schools and lack a strong vision for instructional improvement (Chimerine, Haslam, \& Laguarda, 1994; Fullan, 1991). Another limitation of any external support is that the partners are dependent not only on their own strategies and the intensity of their assistance, but also on school contexts and the behaviors of school staff (Cohen \& Ball, 1999; Fullan, 1991; Sunderman \& Nardini, 1999).

The literature on intervention thus suggests several elements for our analysis of support providers' strategies: the aspects of instructional capacity (teachers, materials, students, school environment) that external partners and probation managers target in their effort to improve probation schools, the extent to which these represent a clear vision and strategy for intervention, and the type and intensity of learning opportunities they provide to school personnel. These learning opportunities are discussed in more detail below.

\section{Opportunities for Professional Learning}

A key feature of organizational capacity is the consistent structuring of opportunities for teachers and administrators to learn what is needed to improve practice. Providing such opportunities is one of the central tasks of the external partners and, with respect to principals, of the probation managers. The literature on professional development suggests that accomplishment of this task, however, requires a break with conventional staff development models.

Criticisms of currently dominant forms of professional development for teachers are well known. Surveys of staff development find that it generally consists of "unfocused, fragmented, low-intensity" activities, such as shortterm workshops with little or no followup (Corcoran, 1995). Little (1993) has argued persuasively that conventional staff development is based on a transmission model of learning that is inappropriate for current reform goals and contexts.

Meanwhile, studies of effective professional development have delineated several characteristics found to be related to increased teacher capacity. In their synthesis of the literature, Newmann, King, and Youngs (2000) conclude that "to promote the kind of teacher learning that leads to improvement in teaching, professional development should concentrate on instruction and student outcomes in teachers' specific schools; provide opportunities for collegial inquiry, help, and feedback; and connect teachers to external expertise while also respecting teachers' discretion and creativity." Other researchers have documented the relative effectiveness of professional development that is focused on the content that students are to learn and how best to teach it (Cohen \& Hill, 1998; Corcoran, Wang, \& Foley, 1999; 
Kennedy, 1998). ${ }^{14}$ These findings are consistent with the recent emphasis on content knowledge and pedagogical content knowledge in studies of teacher capacity. In addition, evidence is emerging that this content-based professional development must be of high intensity and sufficient duration before it will have a measurable effect on practice (Hawley \& Valli, 1998; Smylie, Bilcer, Greenberg, \& Harris, 1998). A recent quantitative analysis of the National Science Foundation's Local Systemic Change initiative, for example, found that "it was only after approximately 80 hours of professional development that teachers reported using inquiry-based teaching practices significantly more frequently... while the big change in investigative culture came only after 160 hours" (Supovitz \& Turner, 2000).

The next section concentrates on these elements of support providers' strategies in the Chicago school probation context. We then consider the overall strength of the support system in light of our findings and of a framework offered by Andrew Porter and his colleagues.

\footnotetext{
${ }^{14}$ Fennema and Carpenter (1992) also found significant effects in their work on cognitively guided instruction, which focuses on how students learn mathematics, as opposed to specific strategies for teaching it.
} 


\section{Summary of Conceptual Framework}

The literature reviewed above suggests that an analysis of the system of external support for Chicago probation schools should incorporate several key elements:

- Support providers play an important mediating role in the implementation of the CPS probation policy.

- Implementation issues at several levels are likely to cause variation in the provision of support in probation schools, variation that is further enhanced by the market approach to external partner selection.

- Because of this variation, it is important to consider the theories of action or strategies that providers bring with them into the schools.

- Central to those strategies are:

- Providers' conceptions of the problem of low performance and their vision of teacher and school capacity.

- Providers' targets of intervention: specific elements of the instructional unit (teachers, students, materials) or of the school's instructional environment (coordination and leadership, professional culture, monitoring, and opportunities for adult learning).

- The content, form, and intensity of professional development opportunities that support providers offer or sponsor. 


\section{Provider Strategies and Implementation of Assistance}

To summarize, the provision of the Chicago school probation policy has involved external assistance to more than 100 elementary schools that have been on academic probation since 1996. At minimum, each school worked with an external partner and probation manager. Most also received input and assistance from their regional education office, an Office of Accountability facilitator, and a business manager or intern.

Despite the universality of assistance to schools on probation, the nature and intensity of that assistance varies substantially from provider to provider and school to school. This section describes that variation at the level of the providers. We begin with a brief overview of the assistance provided to probation schools. We then describe the theories of action and strategies of the providers, including the areas identified earlier in this report: the providers' construction of the problem of low performance and goals in working with schools, their targets of intervention into school organization, and the methods and content of their professional development. Finally, we consider several constraints on the implementation of support across providers, which serve to limit the effect of the assistance on probation schools. They also provide the basis for our discussion of policy strength and implications in the final section of this report.

\section{Overview of Assistance}

During the 2000-2001 school year, CPS approved 18 external partners to work with probation schools in Chicago and 16 of these assisted elementary schools. ${ }^{15}$ The four largest of these were university based and worked in $70 \%$ of the probation schools. Twelve others three universities and nine independent consultants - served five or fewer schools. ${ }^{16}$

The background and degree of experience of the consultants ${ }^{17}$ who worked directly with schools on probation varied by partner. For example, the Center for Urban Education at DePaul University employed young teachers who were on loan from CPS for one to two years;

\footnotetext{
${ }^{15}$ For this report, we focus on the external partners linked to the schools through probation, although we have found that many schools work with a number of other external agencies to varying degrees. Our case study data reveal that the role of these additional providers can be very important in any given school, but for the purposes of this report, we mention them only vis a vis their relationship with the probation support system.

${ }^{16}$ The 11 partners that participated in our study are listed in Appendix A. Over the five years of the policy, six of the probation partners have either gone out of business or stopped working with probation schools in Chicago: the North Central Regional Educational Laboratory, Morningside Learning Systems, Malcolm X College, Quality Education Services, Marva Collins, and America's Choice.

${ }^{17}$ The external partners send people with a variety of titles into the schools (e.g., implementation specialists, coordinators, and facilitators). For the sake of simplicity, we refer to these people as consultants.
} 
many of them were graduates of the DePaul Urban Teacher Corps. In contrast, School Achievement Structure employed retired teachers and administrators, while both Community for Learning and Small Schools Workshop hired individuals with a variety of backgrounds, including social workers and psychologists.

In addition to the various external partners, 53 probation managers worked with elementary schools on probation during the 2000-2001 school year. Probation managers are recruited by district staff based on their prior administrative success within and outside of schools. Nearly all of the probation managers we interviewed described themselves as working directly with the principal, and by providing ideas, support, and guidance. A few reported that their work extended beyond the principal to include teacher behavior and knowledge. Overall, however, probation managers described their role in the schools as unclear and undefined.

\section{Construction of the Problem and Goals of Support Providers}

The Chicago school probation policy derived from a perception that persistent low student performance stems from problems of the will and capacity of the people working in the school. In interviews, several district administrators attributed school failure directly to unmotivated or incompetent staff. They described school staff as "going through the motions" and holding low expectations for students. In the words of one district official,
"Most [of the school staff] are in denial. They talk about 'those parents' and lay blame without taking any of the responsibility." Similar sentiments echoed throughout the district-level interviews.

External partners and probation managers also locate the problem of low performance within the schools - either at the classroom or organizational level. Two-thirds of the probation managers participating in our study mentioned problems having to do with low morale, inexperience, or other weak aspects of teachers at the schools. Half faulted weak leadership on the part of the principal, either in addition to or instead of teacher failings. Additionally, nearly all of the external partners thought the primary problems in these schools were related to poor teacher quality and/or weak principal leadership. By contrast, many respondents in the schools point to problems outside their control: poverty, inattentive parents, and dysfunctional communities. This disjuncture between support providers' views and those of school personnel is hardly surprising. In part, probation managers and external partners were brought into these schools precisely to help the staffs redirect their attention to internal beliefs and behaviors that may be inhibiting student learning rather than focusing on factors external to their schools. According to one probation manager:

People had to wake up and start focusing on instruction and teaching and learning. The schools on probation are the ones racially isolated and in lowincome communities. You don't see any 
schools on probation in upper-class neighborhoods. But in some of the poorer communities, you have schools next to probation schools that are doing well. So there's something dysfunctional within the school...In many cases, people use [external causes] as an excuse, but you can do that no longer.

Interestingly, while both external partners and probation managers asserted that school staff needed to change their beliefs and expectations about students, very few mentioned such change as among their own main objectives, and none seemed to target teachers' beliefs about students in any systematic way.

Beyond pointing out the internal nature of the problem, support providers varied in their description of its source or solution. A few focused on matters of will, noting that there were too many teachers who simply were "not teaching." Others acknowledged low motivation but attributed it to teachers feeling beaten down and blamed - in part by the negativity of probation reports and media coverage. Such determinations affected providers' approaches to working with school personnel. For example, Barbara Radner of the Center for Urban Education sees teachers as "depressed" and therefore uses an "asset-based approach," which avoids direct criticism of either teacher behavior or ideas, instead seeking changes through reinforcing their positive manifestations. Radner says teachers are "individuals who have been working hard, are discouraged, and feel devalued."
Whatever the approach to motivational issues, probation managers and partners concentrated their attention most directly on problems of capacity. Teachers' knowledge and skills were at the heart of the partners' assessment of school needs. Sharon Ransom of Northeastern Illinois University and Barbara Radner of the Center for Urban Education, for example, both point to the limited knowledge base of teachers due to inadequate pre-service training. In the words of Ransom, "Teachers need to have new ideas followed up on and time to try out the strategies...In some cases we are doing teacher training and not professional development." Consultants with School Achievement Structure, by contrast, noted the disorganization of instruction, pointing out that neither curriculum nor individual lessons are well-structured or paced. Few external partners identified content knowledge as a central problem, with the possible exception of Radner, who pointed out "elementary [teachers] are methods happy...We have content confusion and methods obsession for elementary teachers." Low principal skills were also aspects of individual capacity noted by partners and probation managers. These inadequate skills included lack of focus, inattention to monitoring of instruction, and poor methods of teacher evaluation.

In addition to low levels of individual capacity, all probation managers and some of the external partners identified larger issues of organizational capacity as especially 
problematic in these schools. ${ }^{18}$ Common criticisms included the absence of a coherent vision and a lack of structure or coordination across the educational program. One probation manager's description of the school he worked with was consistent with many others' comments: "The school was not organized, no mission was in place, and there was no focus in terms of people working together." An external partner supported this perspective, saying that "teaching and learning issues are central, but most of the problems in these schools are problems of organization and management."

\section{Intervention Targets and Strategies}

Providers' approaches to working with individual schools derived from their construction of the problem and conception of capacity. In this section, we describe providers' targets of intervention - that is, those groups or components of capacity on which they concentrated their attention and efforts. We then consider the extent to which such targeting aggregates into a coherent change strategy.

\section{Intervention Targets}

The external support providers' targets of intervention are an important aspect of the theory of action. To indicate the overlapping nature of assistance at the school site, we refer

\footnotetext{
${ }^{18}$ Four of the 11 external partners identified problems at both the instructional and organizational levels. These partners are described below.
}

back to Cohen and Ball's (1999) discussion of instructional and organizational capacity building. A common misconception is that the external partners target the instructional unit (primarily teachers) and probation managers target the environment (principals), but in actuality this simple division of labor rarely holds. Figure 5 illustrates the overlapping nature of the targets of intervention of probation managers and external partners at the school site. As seen in this figure, external partners focused on both the instructional unit and the school environment. To the extent that they focused on the environment, their interventions frequently overlapped with those of probation managers, especially in the areas of monitoring and coordination.

\section{Targeting the Instructional Unit ${ }^{19}$}

As Cohen and Ball (1999) argue, instructional capacity can be improved by targeting some combination of teachers, materials, or students, and especially by focusing on the interaction between these three elements of the instructional unit. Those external partners who viewed low instructional capacity as the problem tended to focus

\footnotetext{
${ }^{19}$ This section on building instructional capacity will only describe the assistance of external partners because probation managers as a rule target organizational, rather than instructional, capacity.
} 


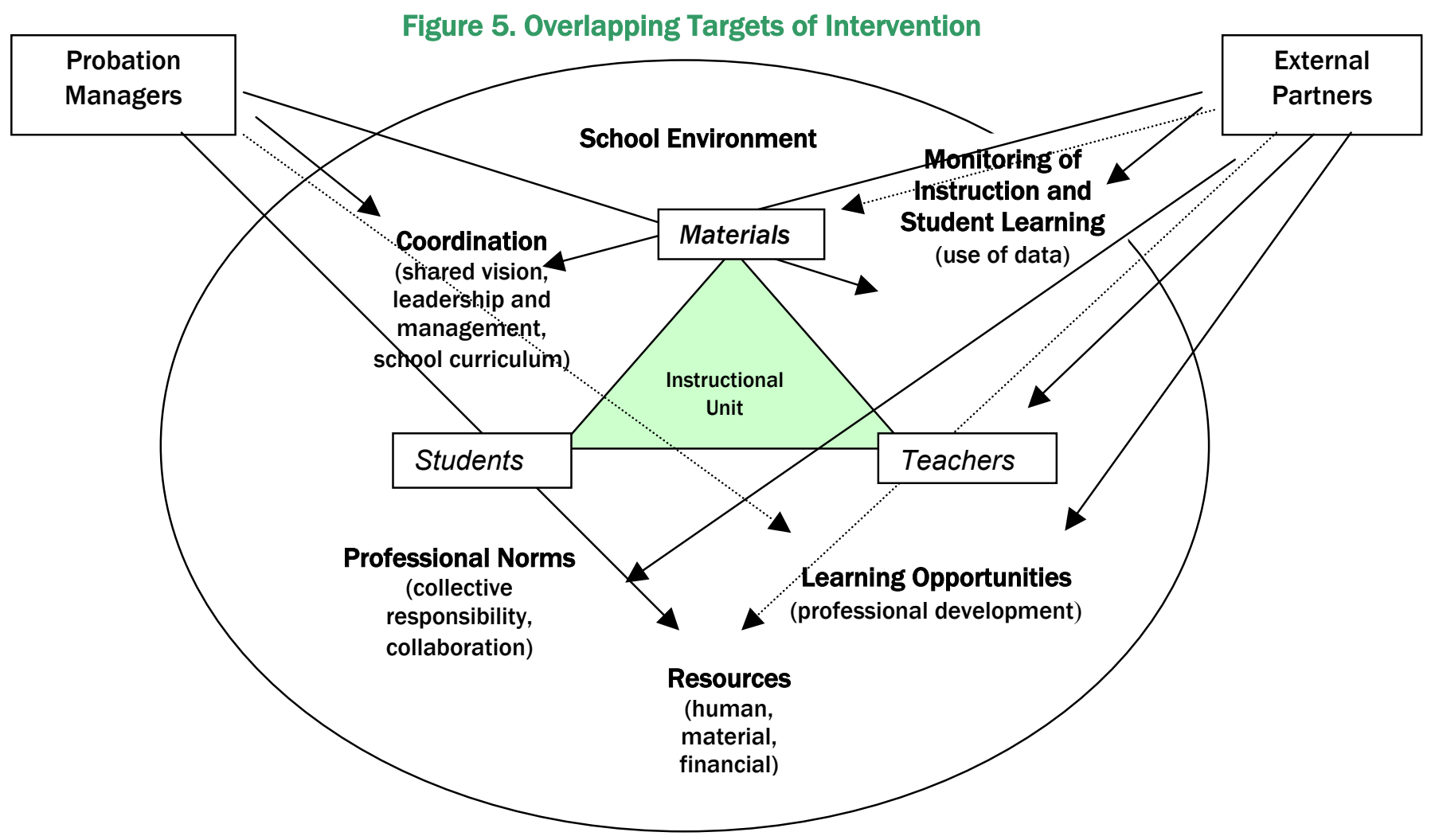

on the classroom, particularly on curriculum and instruction. Among probation support providers, most efforts to build instructional capacity focused on either teachers or materials. ${ }^{20}$

\section{Teachers}

According to Cohen and Ball (1999), teachers are the most promising points of intervention to improve instruction because "teachers mediate all relationships within instruction." Teachers, in fact, were the primary target of the external assistance provided by external partners, although

\footnotetext{
${ }^{20}$ Intervention to improve student motivation and capacity more directly took the form of policies on student promotion and retention and of after-school and summer support for struggling students. For the most part, these interventions were outside the purview of the external partners.
}

the specific teachers targeted varied by partner. For example, some partners limited themselves to working with teachers in the accountability grades while others worked with every teacher in the building. Still others worked only with those ready and willing to receive assistance. These variations occurred within as well as among external partners. The approaches seemed to have more to do with the degree to which individual principals allowed the external partner access to teachers than with the programs of the external partners themselves. In fact, the decisions to target particular groups did not appear to emanate from a clear approach or strategy on the part of external partners.

All of the external partners who participated in our study focused on developing teachers' knowledge and 
skills, but few emphasized content knowledge and learning in the professional development they provided. Instead, the external partners focused on teachers' pedagogical skills, providing tools to help teachers better group students and organize their lessons. In fact, 8 of the 11 partners provided training that emphasized generic pedagogical strategies, including how to effectively organize instruction. For example, School Achievement Structure emphasized pacing and grouping strategies in their "Ten Routines" of effective instruction. Similarly, Community for Learning trained teachers on how to organize students into three ability groups for reading instruction. In a 90-minute reading block, the teacher spent approximately half an hour instructing each small group, while students in the other two groups worked in learning centers or completed independent practice.

Several partners also tried to ensure what they considered to be proper coverage (e.g., making sure the topics on the ITBS [Iowa Test of Basic Skills] were taught during the year) by providing teachers with calendars and other tools for teachers to use to help manage instruction. The tools provided by external partners were meant to guarantee that students were tested on the material they had a chance to study. In a few cases, the tools were meant to expand the instruction beyond ITBS coverage.

Less than half of the partners reported developing teachers' skills in teaching students how to think critically (i.e., teachers' questioning strategies). For example, Achieving High Standards Project worked with teachers to show them that asking particular questions could improve comprehension. They identified three points when teachers should ask questions of students: (1) before reading (e.g., What in my prior knowledge will help me with this particular task?); (2) during reading (e.g., What information is important to remember?); and (3) after reading (e.g., Do I need to fill in any holes in my understanding?). Another example of this type of approach was the Center for Urban Education's focus on having teachers ask challenging questions of students in book discussions. To remind both teachers and students of higherorder thinking skills, the Center for Urban Education provided a poster that summarized the steps to approaching reading: (1) Get it (literal questions to ask), (2) Get it Clear (analytic questions), (3) Think More (inferential questions), and 4) Think it Through (evaluative questions). Although these strategies were more elaborated than others, they, too, emphasized the development of teachers' pedagogical skills rather than their content knowledge.

A few partners focused on pedagogical content skills to some extent. For example, Achieving High Standards Project provided teachers with training and a structure for organizing reading instruction based on the Four Blocks of Literacy. Achieving High Standards Project gave teachers forms to plan each lesson around guided reading, independent reading, word study, and writing. Three of these were to be covered in the 90-minute 
reading lesson at the start of the school day; the fourth was to be picked up at a later time. The Center for Urban Education also provided workshops on specific aspects of literacy instruction, such as the teaching of poetry, but these seemed primarily to provide background to the main emphasis on generic questioning skills.

While all of the partners addressed some aspect of reading instruction, only 4 of the 11 partners that participated in our study reported having a comprehensive reading program. ${ }^{21}$ In our definition, comprehensive reading instruction involves a reading curriculum, a consistent and coherent set of instructional strategies for the teaching and learning of reading, and assessment tools for evaluating student progress. In addition, professional development on reading instruction is sustained over a period of time. Significantly, the four partners that reported this type of comprehensive approach served a total of only 10 of the elementary schools on probation. In addition, across the partners that addressed reading to any extent, the approach to literacy instruction varied tremendously from a focus on fluency to word recognition and phonic decoding strategies. Rarely did a partner emphasize improving teachers' explicit understanding of the reading process

\footnotetext{
${ }^{21}$ We found some instances in which external partners facilitated a school's relationship with a literacy program when they did not provide this within their own program or continued to support a program that a school already had a relationship with. For example, one partner brokered the school's relationship with the Success for All program.
}

and scientific basis of literacy instruction.

\section{Materials}

As illustrated in Figure 4, targeting materials is another way to improve instructional capacity. Although the partners emphasized developing teachers' knowledge and skills through professional development sessions, nearly all of the partners provided some type of materials to facilitate the implementation of new practices and assist teachers in organizing their curriculum and instruction. In addition, about half of the partners in our study requested that schools reallocate their resources toward the purchase of specific instructional materials. The materials the partners provided include charts that match ITBS topic areas to state and district standards, lesson plan guides, "how-to" packets or sheets, and assessments. These materials were often prominently displayed in the classrooms.

While most partners provided these types of tools for organizing instruction, few offered teachers actual curricular materials for use with students. ${ }^{22}$ Only 3 of the 11 external partners provided teachers with an actual curriculum, and one other partner provided short lessons to teachers. Most of the partners worked with the existing basal reading series. Approximately half of the partners provided teachers with

\footnotetext{
${ }^{22}$ While partners did not tend to provide this type of material, the district recently supplied structured lessons as a resource to teachers.
} 
assessment tools to be used regularly in their classrooms. These tools focused on discrete skills assessed on the ITBS.

\section{Students}

Another important strategy for improving the instructional unit is to intervene directly at the student level. Thus, alongside school probation, CPS initiated various programs and policies to target students in these schools. Principal among these were the student promotion policy, the Lighthouse Program, and summer school. The external partners' work, however, was intended to focus on the adults and it did so almost exclusively.

Some schools contracted with other providers to work directly with students. For example, several probation schools contracted with Success Lab, a private company that provides students with extra assistance in reading once a week. During these pullout sessions, trained coaches worked with small groups of two-to-four students. Students read books at their achievement level and, at the end of each session, completed a computerized test that marked their progress. Based on this test, the coach individualized

\section{A Variety of Materials for Schools}

Several partners provided teachers with materials to assist them with new curricular and instructional strategies. The following examples illustrate the variety in the types of materials provided to school staff.

Accountability Direct Instruction Model and the Brad Frieswyk Group emphasized direct instruction of scripted lessons. These partners provided a variety of materials to educators: charts to track reading fluency, protocols to help students build comprehension skills, and direct instruction books and lessons.

School Achievement Structure had educators follow a set of "structured routines" around discipline, instructional pacing, and assessment of skills. These routines are grounded in the effective schools research. School Achievement Structure asked teachers to complete skillspacing charts that document whether or not each skill tested by ITBS has been learned "to mastery levels" - teachers indicated whether students had been introduced to a skill, and when they had reached proficiency. This partner also connected its schools to a software company that provided them with a bank of test items they could draw from for grade-bygrade assessments. 
the program to meet the student's needs. Success Lab's contracts varied by school, ${ }^{23}$ but the company guarantees all schools a refund if they do not see an average of one year's growth across students. ${ }^{24}$

\section{Interaction among Teachers, Students, and Materials}

A couple of the partners targeted teachers and materials together by training teachers in the use of certain types of materials in the classroom. To the extent that the partners worked with teachers directly in their classrooms, they may have also focused, at times, on the interaction between teachers and students. However, the interaction of students, materials, and teachers was not at the heart of what these partners did. For example, little analysis occurred with teachers around student work and the kinds of instruction that produced the work. We did observe one exception to this pattern: teachers who participated in the Center on Urban Education's Saturday workshop shared their students' work around a curricular or instructional area that the teachers learned about the previous week. For example, a middle school science teacher brought books her students made about rainfall and its consequences to the workshop to

\footnotetext{
${ }^{23}$ The contracts tend to cost $\$ 80,000$ to $\$ 100,000$.

${ }^{24}$ In our case study schools that employed Success Lab, however, we saw no attempt to track its impact on student achievement/test scores. We also found no evidence of any attempt to coordinate the work of these other agencies with those of the external partners (or with the general education program of the school, for that matter).
}

discuss with other teachers after they learned about expository writing in a previous workshop. However, our data provide no indication of the regularity or frequency of these activities. It is conceivable that external partners' direct mentoring and observation of teachers in classrooms involved more emphasis on the interaction of these three elements, although neither interviews nor observations indicated a regular pattern in this regard.

\section{Targeting the Instructional Environment: Building Organizational Capacity}

As illustrated in Figure 4, Cohen and Ball (1999) also emphasize the importance of managing the environment around the classroom or basic instructional unit. In the probation system of support, the work of the probation managers and that of the external partners overlapped in terms of the organizational or environmental level of the school. Six of the 11 partners and all of the probation manager respondents focused on the internal school environment or organization to build capacity. The probation managers in our study focused exclusively on organizational capacity - by design, their role is to "mentor" the principal, usually in the areas of management and leadership. In addition, two partners focused exclusively on organizational structures, leadership, and management, often targeting the principal or leadership team. The remaining four of the six partners that targeted organizational capacity did so in conjunction with their efforts to target the instructional unit itself. 
Based on our conceptual framework, we analyze the organizational efforts of external partners and probation managers along four dimensions: coordination and leadership, professional norms for teachers and teaching, resources for learning and instruction, and the monitoring of instruction and student learning. This section describes the variation in, and overlapping nature of, the organizational capacity interventions at the school site.

\section{Coordination}

The support providers' focus on coordination of school-level factors primarily involved working with the principal and/or leadership team to strengthen the school's leadership and to develop a shared vision and common goals across the school's staff. Most of the work of the probation managers targeted coordination as they worked one-on-one with principals, mentoring them by providing ideas and guidance and developing their management skills. One probation manager described his role as follows: "I see myself as a coach, as a devil's advocate, as a brother. I make sure they're doing what they're supposed to be doing." Similarly, School Achievement Structure, Center for Urban Education, and Northeastern Illinois University focused on strengthening the management and instructional leadership skills of the principal.

A common view was that the principals needed to become stronger leaders and, to encourage their development, both probation managers and partners recommended generic strategies to the principals. For example, providers recommended that principals become more visible (in the hallways and classrooms), that they monitor instruction more frequently, and that they follow through with teachers on instructional issues. One external partner, the Valina Miller Group, identified tensions and divisions among staff and leadership as a major barrier to improvement in at least one of its probation schools, and hoped to encourage the school to work more collectively as a team.

Another strategy related to coordination at the organizational level was to assist the schools in developing a common vision and to help them in narrowing their goals and strategies to support this vision. The primary example of this strategy was Northeastern Illinois University's approach, which provided intensive assistance by working with teachers and administrators at a school site to develop a set of common goals and a school-wide vision. Northeastern Illinois University saw this as a key leverage point for school improvement. Similarly, 3 of the 11 partners and 5 probation managers reported working with the school on the planning process, but this was done on a much less intensive scale than the needs assessment and strategizing work of Northeastern Illinois University. For example, some of the partners helped the schools by developing and administering surveys to inform their planning for the following year. 


\section{Helping Schools Identify Needs and Focus}

To begin a partnership with a school, Northeastern Illinois University conducted a collaborative needs assessment. After meeting with the principal and the school's leadership team to discuss visions and belief systems, Northeastern brought the entire faculty together to meet with its team of 8-10 faculty members and consultants. In small groups of six-to-eight teachers, the Northeastern facilitators posed one significant question: "What in your opinion could you/we do that would increase student achievement?" The facilitators asked questions and got everyone's input. Heather Patay, Northeastern's director, described the process: "We go around a few times on the question. As time progresses, you get layers of responses. Then we come back and ask people to choose their three-to-five top priorities." She believed that one of the advantages of this approach was that it respects the strengths of the school. The work plan that was developed from this process allowed Northeastern to build on what was happening at the school. "This is the first step in dialogue and building trust," said Patay. "This way, we prioritize what's important."

\section{Professional Norms}

Some managers and partners also targeted one of the most difficult areas to change in schools: professional norms. The two institutionalized norms of particular concern were the isolation of instructional practice and the inadequate use of data. A handful of support providers (both probation managers and external partners) mentioned trying to change teachers' beliefs about students (i.e., their low expectations), but systematic efforts in this direction were difficult to detect in our observations and interviews. ${ }^{25}$ As mentioned previously, an overall goal of the external support system was to facilitate the school staff's internal examination of problem areas contributing to the school's low

\footnotetext{
${ }^{25}$ We detected no regular efforts in this regard either in our interviews of probation manager and external partner respondents or in our 10 case study schools.
}

performance. However, as one probation manager observed, they were not trained in working with the schools to facilitate this process.

Several external partners targeted organizational structures that, once implemented, would facilitate teachers sharing ideas and practices, rather than teaching in isolation. A common approach recommended by the external partners was the establishment of gradelevel teams or clusters. Two probation managers also encouraged more interaction and discussion among teachers, with the goal of having them share their ideas and practices with their colleagues. Such structures and practices have potential not only for fostering learning, but also for better coordination of instruction throughout the school. One probation manager, a sitting principal, created an exchange program among his teachers and the probation school's teachers. 
In addition, the partners and probation managers reported efforts to develop educators' knowledge and skills around the use of student data to inform classroom instruction. Two partners, School Achievement Structure and Community for Learning, collected and analyzed data to determine student progress and, subsequently, reported their findings to the schools. In addition, four partners encouraged schools to focus more on their student performance data, but did not provide intensive assistance to the schools so that they learned how to analyze the data without the help of the partner. While the external partners emphasized the use of data in the classroom - to help teachers determine ability group placements and level of mastery - a few probation managers encouraged administrators to use the data as a monitoring tool and part of the planning process, as discussed in more detail in the section below on monitoring. We found little evidence of communication between partners and managers about these overlapping strategies regarding the use of data.

\section{Resources for Learning and Instruction}

Another way in which the partners and managers leveraged change at the organizational level was by garnering and brokering resources for the schools. In some cases, this began with attention to resources currently in place in the school - primarily personnel. One School Achievement Structure consultant said, "I also go to the principal and ask to see the qualifications of his teachers. I might find that a first-grade teacher has no primary certification. I'll ask, 'Why don't you get someone in there who has the proper certification? Or make that teacher aware they need to go back to school.'" A few of the probation managers went as far as identifying teachers whom they thought the principal should replace.

Both partners and probation managers reported they informally responded to a school's identified needs by referring the staff to appropriate organizations to assist them or by helping the principal navigate the district's system. For example, Northeastern Illinois University connected teachers to the library of teaching materials available at the Chicago Teachers' Center. In addition to brokering resources, more than half of the external partners pushed schools to reallocate resources to pay teachers stipends, to purchase materials, or to hire new personnel. When reallocation was not possible, the partners appealed to CPS or another organization for funds to implement these changes.

At times, the partners brokered services because of limited capacity within their organizations. For example, several partners had their schools subcontract with an independent organization to assist with the writing and scoring of five-week assessments. In some cases, when the brokered services were monitored and coordinated by the external partner, they appeared to be an effective means of extending the partner's capacity. In others, however, multiple partners appeared to contribute to a fragmentation of support 
and even conflicting messages or processes. We discuss this problem under implementation constraints below.

\section{Monitoring of Instruction and Student Learning}

Effective use of information is a central feature of high-performing organizations (Mohrman \& Lawler, 1996). External partners and probation managers worked with school staff on the monitoring of information at the school level in three areas: student performance, classroom instruction, and implementation of improvement plans and programs.

Frequent monitoring of student performance is a characteristic of "effective schools" (Edmonds, 1979). As mentioned above, external partners and probation managers worked with schools to increase the use of data in monitoring overall school progress and making decisions about school improvement planning. For example, 4 of the 11 external partners discussed the results of ITBS data with school staff to identify the collective strengths and weaknesses of students. None of the partners or managers reported analyzing state assessment data, although this is not that surprising since probation is based on the ITBS, not the IGAP (the Illinois Goal Assessment Program).

A few external partners and most of the probation managers emphasized the importance of increased monitoring of instruction by the principal. They encouraged principals to visit classrooms to check that teachers were actively teaching and were using the designated materials. They also supported the regular review of lesson plans. Information on instructional practice was generally less systematic in either its collection or interpretation than were student achievement data, however. For the most part, partners and probation managers seemed to focus on the principals checking to see that teachers were teaching and that there was at least minimal compliance with the approved instructional program.

Both probation managers and external partners monitored the implementation of the reform process in the school, including their own programs and of the school planning process. Although monitoring the School Improvement Plan for Advancing Academic Achievement is an area that falls under the districtspecified responsibilities of the probation manager, only one-quarter of the probation managers interviewed mentioned involvement with this planning process. More frequent monitoring of overall school performance occurred through the regular evaluations that the partners and managers provided to CPS. Three of the 11 partners evaluated the degree of implementation at the school site through site visits to observe classroom instruction and discussions with school staff about their improvement efforts. Neither partners nor probation managers reported having consequences or strategies in place that would be implemented when scores were not increasing or when schools 
were not improving by some other measure.

The probation managers' informal role of monitoring the external partners was not clearly defined but was mentioned in district and probation manager interviews. For the most part, the managers felt that the partners were providing much needed support to the schools - only 1 of the 16 probation managers involved in our study cited problems or concerns with an external partner. Two probation managers had recommended that their schools select new partners, basing these recommendations on their view that the "fit" was bad, not that the partners' programs were weak or misguided.

\section{Evaluating Program Implementation}

Two external partners developed strategies to determine the degree of implementation of their program and/or the school's improvement plan at each school. The external partners followed up after the visit, identifying weak areas of implementation.

The School Achievement Structure Impact Visit took place over a two-day period, wherein several School Achievement Structure consultants observed classrooms to gauge how well the school was implementing the improvement plan and the organization's Ten Routines. The group wrote a report and then met with the school's leadership team to address the findings and design remedies. The School Achievement Structure team returned at a later date to determine whether or not the school had corrected the identified problem areas. Its goal was for their schools to internalize this process and become responsible for their own monitoring.

The Grand Rounds Review was one component of the Center for School Improvement's quality-assurance system. The process began with schools completing a self-study in three areas: literacy, social services, and leadership. Teachers reflected on their use of the literacy framework in classroom practice. This self-study was combined with an observation by the school's literacy coordinator. The two sources of data were aggregated across all teachers and provided a profile of the depth and quality of the implementation of the literacy initiative. Center for School Improvement staff and the school's leadership used these findings to review school operations and plan for the future. 


\section{Change Strategies}

As is evident from the preceding discussion, external partners and probation managers targeted multiple aspects of instructional capacity. The ultimate question is whether these targets added up to effective strategies for changing the organization and improving instructional practices throughout the school as a whole. Put another way, how strategic was the work of the external partners and probation managers overall? How did these groups attempt to leverage, disseminate, and sustain more effective practice?

Unfortunately, we found that most of the probation managers and external partners lacked a strategic approach to bringing about school-wide improvements. Few had wellarticulated strategies, targeting instead a variety of different problem areas at the school and/or the classroom level apparently on the belief that small changes in these areas would eventually cumulate over time. A few of the external partners, however, had thought through a more connected approach for leveraging organizational change or disseminating new practices. One such strategy focused on collective visionsetting and the brokering of services consistent with that vision (a classic organizational development approach) on the theory that collective buy-in was the key element to successful change. Another strategy emphasized strengthening the leadership structure of the school on the belief that monitoring and controlling teacher behavior was key. With respect to instruction and the dissemination of more effective instructional practices, most partners relied on general workshops and fairly ad hoc observations of individuals.

Two more systematic strategies were evident among a handful of partners: the train-the-trainer approach and onsite literacy coordinators. The train-thetrainer approach involves a few school personnel attending workshops and then being responsible for enlightening their colleagues at the school site. Our observations in the case study schools suggest that this model suffered not only from the usual dilution of such approaches but also from inadequate preparation of the trainers themselves. A more promising strategy appeared to be the provision of a well-trained, fulltime on-site coordinator in particular curriculum areas - primarily reading, as practiced by Success for All and the Center for School Improvement. These individuals were better prepared in the content areas than is usual in train-thetrainer approaches, and they held a structural position in the school that allowed them to work more closely and consistently with staff over an extended period of time. This approach is consistent with the literature on effective adult learning as discussed in this report.

\section{Opportunities for Adult Learning: Methods and Content of Professional Development}

Whatever the leverage points for organizational change, all probation managers and external partners are responsible for providing professional 
development opportunities to teachers and/or administrators at the school site. Our review of the literature on effective professional development emphasized that it should be focused on both content and pedagogy; that it provide opportunities for inquiry, help, and feedback on actual practice; and that it be of sufficient intensity and duration. Conventional reliance on short-term workshops isolated from practice has been particularly criticized.

Unfortunately, the majority of external partners' assistance continued to reflect the conventional model of fragmented, one-shot professional development opportunities. This conventional professional development frequently took the form of half-day and full-day workshops and training sessions occurring either during the school day or on weekends. ${ }^{26}$ Six of the 11 partners (working with 61 schools) primarily provided this type of professional development, mostly during restructured days. The topics of those sessions were diverse, ranging from implementing learning centers to teaching reading. A few of these partners focused staff development on helping teachers understand the value of grouping students for instruction (e.g., ability grouping) within each class and/or grouping students for reteaching of particular concepts not mastered on frequent assessments. We found little evidence of partners having teachers reflect on how the professional development offered in workshop formats would (or subsequently did)

\footnotetext{
${ }^{26}$ Three partners (working with 19 schools) offer week-long workshops.
}

influence their individual classroom practice.

Beyond conventional professional development, all partners reported working with individual teachers, primarily by modeling behaviors and by observing and providing feedback on teachers' classroom instruction. Partners reported "observing" teachers in their classrooms, although this activity apparently ranged from formal observation to an informal walkthrough. In the course of their observations, the consultants reportedly focused on how well teachers implemented the routines, practices, or strategies from the workshops. An example of this type of assistance observed during the study involved a consultant working side-by-side with the teacher on a direct instruction lesson. The consultant began by modeling the instruction; he then observed the teacher implementing the same step.

The one-on-one assistance provided by partners varied in its frequency and intensity. Some of the consultants reported observing and providing feedback to teachers each time they were on site, but the number of teachers receiving this type of assistance was difficult to determine. For example, one partner reported that its consultants assisted four teachers a day, on average, but what exactly this assistance entailed and how much time was spent with each teacher was not clear. Nor was it clear how often the consultants followed up on those visits. In our case study schools, for example, we found that many consultants spent about a day 
each week at the school going from classroom to classroom, observing teachers, providing feedback, and distributing materials. Unfortunately, the lack of consistent follow-up to these individual sessions was a common theme among the teachers in these schools - presumably because the consultant's time was spread across a large number of teachers at the site. Support providers had various approaches to rationing their time and assistance to respond to this issue. In many cases, they chose to focus primarily on the teachers who requested assistance, while perhaps stopping by the classrooms of other teachers to see if they needed help. In a few others, consultants had more scheduled approaches. For example, one consultant worked in the school one week every month, spending a day each with the five grade-level teams in the school.

Although most partners reported providing at least some one-on-one assistance as part of their programs, we found that the purpose of that assistance, which mostly was in the form of modeling behaviors, was not always clear to the teachers. In some cases, the assistance appeared to serve as a way for consultants to prove their legitimacy to school staff, especially initially. As one consultant reported, "In September and October, we model. We meet later and talk about it. Fifty percent of it is they're evaluating you. I want them to say, 'I need to try this.' They're not understanding that modeling is for [them] to do it."
Probation managers also used observation and modeling techniques with principals. Like that of external partners with teachers, however, probation managers' assistance to principals varied and was generally of low intensity. Probation managers reported that they met with principals (at most) a few times a month to help them with leadership, management, and monitoring of the school. A couple of external partners (but no managers) facilitated the development of principals' knowledge and skills through networks in which principals had the opportunity to share ideas and get advice. These networks also introduced the principals to research, allowing them to strengthen their bonds to other principals and receive encouragement in their school improvement efforts.

Beyond standard professional development opportunities, 3 of the 11 partners offered courses for which teachers received college credit. For example, Accountability Direct Instruction Model implemented an evening class for teachers to deepen their understanding of how to use direct instruction techniques in the classroom, and the Center for Urban Education offered a 12-week course for teachers that focused on reading instruction. The Valina Miller Group customized a semester course for interested teachers in one of its schools. Teachers selected the topics to be covered and received college and continuing education credits for their participation. Topics tended to be disconnected, however, and the "course" syllabus took on the appearance of a series of workshops 
rather than an integrated investigation of a particular area. Nonetheless, these courses were more intensive opportunities for teachers to learn about new curricular and instructional strategies with other teachers from their schools. Unfortunately, we do not have data on their ultimate effectiveness.

\section{Implementation Constraints of External Assistance}

All of our evidence points to the fact that probation schools were universally receiving assistance from probation managers and external partners. The variation in strategies that we have described is consistent with what we would expect in a generally market-

\section{An Extended Class Asks Teachers to Explore New and Current Practices}

Jean Spencer is a 26-year veteran of CPS who retired eight years ago and became a reading consultant for DePaul University's Center for Urban Education after teaching early literacy workshops across the country. Her experience as a consultant to probation schools led Spencer to believe that teachers "need to spend more time looking at the latest research for new ideas and validating what they're doing and then sharing it with each other in a more structured way than in common planning." At Pickard Elementary, she designed a 12-week course on rethinking approaches to literacy instruction. The course, which met for two hours on Monday afternoons and was taken for credit, had three elements: independent reading, discussion and lecture, and a sustained inquiry by teachers. Throughout the course, she asked teachers to be reflective about new and current practices. Spencer said, "My thing is, 'Why am I doing this?' Is it best practice? Who says it is? How do we know it's best practice? What are your experiences with it?"

She began each class with 30 minutes of reading time, during which teachers selected from professional books and journals. In essence, she was modeling the "Drop Everything and Read" technique. The teachers kept a double-entry journal on their readings, indicating what they read and how they planned to use it in their classrooms. Next, Spencer would lead a discussion around recent research (e.g., reciprocal teaching) in which teachers and students take turns discussing a text. She would supplement the readings and lectures with videos of classroom lessons and concluded each class with a focused inquiry in which teachers chose a topic, generated questions, and answered them. At the end of each class, teachers completed an exit card indicating what they learned, how they planned to use it, and what they still needed to know. To follow up, Spencer was present in the building one day a week to meet during common planning times. She reported that teachers were more actively seeking out new ideas grounded in research, giving them a deeper understanding of what students need to become good readers and writers. 
based support system. In addition, the parties interviewed for this study reported general satisfaction with the support system. ${ }^{27}$ Random samples of probation principals rated both external partners and probation managers fairly highly, although probation managers were viewed slightly better than external partners. One complaint the principals had about partners was that they did not appropriately adjust their program to the school site. Similarly, nearly all of the probation managers in our study had good things to say about the partners; only one thought there was too much paperwork and another expressed concern about a particular partner. ${ }^{28}$ External partners, however, were somewhat more critical of both the principals and the probation managers, expressing frustration that the former did not always follow their programs and the latter were not involved enough with their schools.

Despite the apparent mutual satisfaction, our analysis suggests several problem areas that we believe will limit the impact of this support system. These areas, while overlapping, fall into the following five categories:

- Low levels of intensity;

- Lack of communication among providers;

\footnotetext{
${ }^{27}$ We should note here, however, that comments from teachers in our case study schools are considerably more varied in their estimation of the support providers in their schools.

${ }^{28}$ Two probation managers complained about a former external partner that is no longer working with probation schools.
}

- Uneven targeting of literacy instruction;

- Lack of clear strategies for organizational change; and

- Reliance on traditional professional development strategies.

Each of these is discussed in more detail below.

\section{Low Levels of Intensity}

While varying among providers, the intensity of assistance delivered to probation schools is, we believe, simply inadequate to address the substantial needs of the individuals and organizations concerned. To determine the intensity of the support, we estimated the number of person days per month that the partners and managers worked (in some way) with the schools. On average, external partners spent one-to-two person days a week assisting each school (which was then divided among attention given to individual teachers). ${ }^{29}$ For example, two partners had consultants in the building two days a week but one sent a general consultant for two whole days, while another sent a math and a reading specialist, who spent two half-days each. Similar to external partners, the amount of time probation managers spent in the schools varied. Most of the probation managers reported being in the school two-to-three times a month, with the rest at the school once a month or less. A few managers mentioned that

\footnotetext{
${ }^{29}$ Some of the partners have changed the level of intensity over time.
} 
their involvement was more intense at the beginning of their relationship with a school, but had lessened over time. This is consistent with our case study data, which suggest that while assistance from the probation manager may have been salient in the initial stages of the probation process, it had become less so by the second or third year of probation. The turnover of probation managers at the sites also tended to fragment and weaken their assistance. Finally, both partners and managers reported scaling back what they had originally planned because of limited time and resources and bigger needs at the school level than anticipated.

The variation in intensity of the external partners' support was originally connected to cost, but this is no longer the case because most of the partners' services now cost approximately $\$ 45,000$. In addition, during our study, 41 of the probation schools received federal grants from the Comprehensive School Reform Demonstration program that covered the entire cost of this support. Two partners, Northeastern Illinois University and School Achievement Structure, lowered their original fees of $\$ 90,000$ to $\$ 100,000$ a year to the same level as the rest of the schools. This shift to a common amount charged for services seemed to coincide with the schools paying for the support out of their own budgets and the Comprehensive School Reform Demonstration grants becoming more widespread.
Some partners attempted to extend the reach beyond the time that the consultants were in the schools through train-the-trainer approaches and on-site literacy coordinator models. ${ }^{30}$ Our observations in case study schools suggest that professional development in the train-the-trainer model was much too weak to extend into other teachers' practices. On-site literacy coordinators, however, such as those trained through the Center for School Improvement, received extensive development in literacy instruction and remained on site on a full-time basis to assist teachers and coordinate and monitor instruction.

Their roles as instructional leaders in the schools seem to be a promising approach for enhancing organizational and instructional capacity of schools.

One apparent consequence of the limited time most external partners were in the schools, coupled with the demands for immediate improvement on the test scores, was an impatience among some external partner consultants such that the assistance devolved from "capacity building" into what we have termed "capacity substitution." In theory, the external partners worked with school leadership (e.g., observing and monitoring classes and offering feedback to teachers).

\footnotetext{
${ }^{30}$ Three of the schools in our 10 case studies used on-site literacy coordinators or coaches. In one school, the coordinator was an integral part of the literacy program. In another, the literacy coordinator was connected with Success for All and worked half-time to provide support - an intervention brokered by, but not provided by, the school's external partner. In the third school, the school hired one person to work part-time as a literacy coordinator. This hiring was unrelated to the work of the external partner.
} 
However, what we found in many cases was that the external consultants did this work themselves. For example, in three schools, rather than guiding the assistant principals in how to run gradelevel meetings, the consultants served as substitutes for these staff and led the meetings themselves. The assistant principals, relieved of this responsibility, attended to other duties. While this enabled administrators to respond to day-to-day issues as they emerged, when the school reduced or ended its partnership, there was no one to take on this important task. Similarly, several partners wrote the reading plans for their schools. Rather than using this as an opportunity for the school to adapt the reading instruction program to suit its individual needs, the partner supplied the vision and program to the school.

\section{Lack of Communication among Providers}

The lack of communication among providers (external partners with other partners and probation managers with other managers) is noteworthy. Both external partners and probation managers met with district administrators, but these meetings appeared to be focused on administrative procedures, rather than on the sharing of successes and failures. Perhaps more important, however, was the need for communicating between these two types of support providers, especially when the partner intervened in the environmental level of the organization. Unfortunately, we did not observe or hear evidence of probation managers and external partners actually collaborating, or even communicating, about their overlapping strategies.

Beyond official probation partners, multiple other external agents provided assistance to these schools. Communication among these agents and probation partners was at even lower levels, a situation we expect may limit the effectiveness of the policy's external support system. When various groups involved in the same effort have contradictory theories of action, the group's effectiveness is severely limited (Hatch, 1998). While in the probation schools the efforts of managers and partners are not contradictory by design, the existence of multiple groups heightens the probability that school staff will be forced to contend with conflicting messages about school improvement. In fact, half of our case study schools had multiple partners with overlapping strategies. As a result, opportunities for real school improvement were duplicated, contradicted, or lost.

\section{Uneven Targeting of Literacy Instruction}

One rather surprising finding, both from our interviews with support providers and our observations in case study schools, was that the support providers, overall, implement strategies that only weakly attempt to improve literacy instruction. More than half of the partners implemented uneven and low-intensity strategies that were not comprehensive attempts to improve teaching and learning around literacy. This finding is problematic considering schools are placed on probation as a 
result of low reading scores on the ITBS and an implicit understanding at the district level is that the support provided would improve reading achievement. The wide-ranging problems or issues that the support providers identified in the schools, from the facility to leadership to instructional capacity, resulted in a weak instructional focus. While the external partners and probation managers tended to develop generic strategies to improve the instructional unit and the environment, these strategies were not directly linked to literacy.

An additional issue at the school site was that approximately $50 \%$ of schools on probation had switched partners over a five-year period, causing the school staff to constantly adapt to new programs with different curricular goals and interventions. For example, one of our case study schools switched partners, changing from a partner with a constructivist approach to one with a direct instruction philosophy. In our case study schools, we also witnessed a high level of turnover of consultants at the school site (within partners). At times, this had the same effect as switching partners as consultants identified various targets of intervention rather than solely focusing on literacy instruction.

\section{Lack of Clear Strategies for Organizational Change}

While all of the probation managers and some of the external partners targeted the environmental level of the school organization, they did not articulate a comprehensive intervention strategy based on a theory of action. Most of the external partners that focused on this level of the organization did not integrate this intervention with their instructional strategies, leading to a fragmented approach to change. The probation managers implemented a more narrow approach to school improvement, focusing solely on the environmental conditions. Not surprisingly, however, expertise as an administrator did not automatically lead to the ability to transform a lowperforming school from the outside. In fact, improving the performance of these schools appeared to have been more difficult than most probation managers expected. They expressed frustration with the slow progress, reporting that unreceptive, distrustful staff sometimes disregarded their recommendations.

\section{Reliance on Traditional Professional Development Strategies}

A final area of concern is the reliance on traditional professional development strategies - primarily workshops with little intensive assistance to teachers. This type of low-intensity assistance has been found to have limited or no effect on teaching and learning (Supovitz \& Turner, 2000). Although substantial resources from the schools and district were allocated toward external support, the level of intensity necessary to improve the instructional capacity of such a large number of probation schools may, in fact, be difficult to attain. At the very least, content-specific professional development is critical to improving the knowledge and skills of teachers around 
literacy instruction. In the current system of support, the reliance on uncoordinated professional

development opportunities, which were not sustained over time, limited the support provided through this policy. 


\section{Strength of External Support and Implications}

What do we make of the patterns of support described in the previous section of this report? What would we predict to be the likely impact on probation schools? One obvious conclusion is that, through its allocation of substantial resources and attention to the external assistance efforts, CPS has demonstrated not only a recognition of the need for capacity building in its lowperforming schools but a commitment to its realization. Few jurisdictions have, from the outset, designed an accountability system with this level of commitment to school assistance. Moreover, the incorporation of multiple layers of assistance reflects the district's recognition of the variability in school contexts, focus on the "fit" between the providers and the schools, and attempt to involve the broad educational community, including institutions of higher education, in improvement efforts.

Unfortunately, our second main conclusion is that despite the millions of dollars put into assistance, the support component of the probation policy is simply too weak to make it through the many layers of implementation to significantly alter classroom instruction. This conclusion is supported by our case study data. A strong, direct, and observable impact of the external partners on classroom instruction was only evident in 2 of the 10 schools. In the other schools, respondents pointed to a number of problems in the provision of support: high external partner turnover, inadequate expertise of the consultants working with the school, inconsistency between the external partner program and school philosophy, redundancy of the external partner program with other programs, and lack of connection between the external partner's professional development and the identified needs of the school. These problems, combined with the low intensity of assistance, limited the impact of the external partners on instruction. Moreover, the vague focus of the support providers became further diluted as it worked its way through the particularities of individual school contexts. In most of the schools in our study, we found little consistent, concrete guidance around literacy instruction and variable evidence of the impact of assistance on the behavior of professionals in the school.

\section{Policy Strength}

In this final section of this report, we detail our conclusions about the overall strength of the probation policy and suggest implications for change. We do so by re-exploring our findings in light of a framework developed by Andrew Porter and his colleagues to examine curriculum policy. ${ }^{31}$ This framework analyzes variation in policy strength as occurring along four dimensions: prescriptiveness, consistency, authority,

\footnotetext{
${ }^{31}$ These definitions differ slightly from Porter, Floden, Freeman, Schmidt, and Schwille (1988). For example, we include resources committed to a policy as part of the power behind the policy. We distinguish this from authority in that power implies concrete or material consequences or inducements.
} 
and power (Porter, Floden, Freeman, Schmidt, \& Schwille, 1988).

Prescriptiveness refers to the degree of specificity in the policy. In curriculum policy, for example, broad standards would be less prescriptive than a more elaborated scope and sequence, which would be less prescriptive that a mandated curriculum and instructional materials. Consistency refers to the coherence among different policies and policy elements and is, of course, a central tenet of standards-based systemic reform. Policy authority may derive from varying sources, such as professional expertise or hierarchical position. And policies get their power from the extent of the resources committed to their enactment as well as from the constellation of rewards and sanctions accompanying them.

It is important to note that these attributes of policy are not necessarily additive or even altogether independent of one another. For example, consistency among policies may have a multiplicative (rather than merely additive) effect on the strength of each. By contrast, a high degree of prescriptiveness may actually undermine a policy's authority by failing to honor the professional knowledge and discretion of teachers. Policy strength, therefore, may derive more from achieving a proper balance of the components outlined by Porter et al. (1988) rather than from high levels of each. Be that as it may, the bottom line is that for policy to have an impact on instruction, implementers need to know what policymakers want them to do, policy goals have to be consistent with other demands on practitioners' attention and time, and practitioners need to have a reason to expend effort in the direction of the policy. The authority and power behind the policy are meant to provide that reason.

How does the external support system associated with probation fare along these dimensions?

\section{Prescriptiveness/Specificity}

We have already noted that the support policy is purposefully nonprescriptive in order to allow for a better match between partners and the needs of their schools. On the one hand, the market approach to partner selection engenders the desired variation and flexibility in partner strategies. On the other, the vagueness in the purposes of assistance may undermine quality control and overall effectiveness. For example, the requirements of the RFP (Request for Proposals) for prospective partners did not stipulate a focus on improving literacy instruction, so it should not be surprising that few partners had a coherent literacy approach. Yet, the research suggests that without such an approach, there is little hope of significantly altering the ways teachers teach reading. In addition, the huge scope of the five areas designated in the RFP increasing student achievement, improving school leadership, establishing a student-centered learning environment, providing effective professional development opportunities, and promoting parent/ community partnerships - may encourage partners to spread their efforts too broadly, diluting their 
potential for impact. Indeed, the data presented in the previous section suggest that partners were all over the map in their orientation to improvement, often overlapping or duplicating the work of other providers.

Perhaps if probation schools had the capacity to carefully evaluate the partners' approaches and track records, such variation would not be a problem. However, most probation schools have difficulty identifying their own needs, much less the promises and designs of external providers. Our interviews with principals indicate that the building leaders in schools that came off probation quickly (within two years) were much more systematic in their selection of partners than were those principals of schools that remained on probation. The successful principals reported that they already had a vision for what they wanted to accomplish in their improvement efforts and chose a partner to support those efforts. In the less successful cases, partner selection seemed to have been a product of who the principal had met or worked with previously.

Probation managers did not fare much better than external partners in terms of the specificity of their role and focus. Probation managers reported that they received very little guidance as to what they should focus on in the schools and no training on how to be effective interveners and mentors. Rather, this part of the program seemed to rest on the faith that probation managers would choose the right targets based on their own prior success. Unsure of their actual role, however, probation managers were forced to invent it themselves and hope for the best.

Finally, it is important to note that the one area of prescriptiveness in the policy was its emphasis on ITBS scores, which may have had the most constraining influence on practice by encouraging low-level test preparation activities.

\section{Consistency}

On the surface, the support system is highly consistent with other policies, particularly in the emphasis on raising test scores. The fact that the ITBS is used for student promotion decisions as well as for probation reinforces the test's impact (for better or worse) on both policies. By contrast, both the state test and the Chicago Academic Standards appear to take a very secondary role in the work of the providers and the schools. Claims of alignment of the tests and the standards are commonplace but the evidence is slim. Moreover, it is the ITBS and not the standards that drives the curriculum. Partners talked about ensuring coverage of tested skills and mapping curriculum onto the test specifications (rather than onto standards themselves). To the extent that the Chicago Academic Standards are supposed to be at the core of the reform efforts and that the ITBS is an inadequate assessment of those standards, this emphasis on the test in curriculum development is problematic.

Inconsistencies among providers are also a substantial design and implementation issue in the current support system. Not only did the targets 
of external partners and probation managers overlap in the schools, often with inadequate communication between these groups, but also the addition of the regional education office and Office of Accountability facilitators extended the likelihood of conflicting messages to schools. Similarly, the existence of multiple partners not connected with probation enhanced the likelihood of fragmentation and inadequate focus.

Finally, as the district seeks to tighten its control through greater specificity, new avenues of potential inconsistency open up due to variation previously created by the market. For example, the Targeted Assistance Program, which provides additional (federal) monies to low-performing schools to reduce class size in the primary grades, required that participating schools institute 90-minute literacy blocks in the morning and that reading instruction during these blocks be at grade level for all students. This requirement directly contradicted literacy programs already implemented by some probation schools that grouped students by instructional level for reading. Success for All is the most obvious example of such a program. This inconsistency forces schools to refuse the additional resources or undermine what may be a functional reading program.

\section{Authority}

At first blush, the assistance components of the probation policy carry considerable administrative authority. Assistance is not voluntary as it is in some jurisdictions (e.g., Kentucky). Schools must contract with a partner and must have a probation manager. Moreover, the manager is at the school in part to monitor the improvement efforts, a role that suggests additional authority.

Once the providers are inside the school, however, their authority becomes ambiguous at best. For example, the ability of schools to "fire" an external partner makes the partner vulnerable, transforming the role from one of a partner to that of a vendor. Vendors sell services, which consumers are under no obligation to accept or utilize. In addition, while probation managers have responsibility for monitoring the implementation of the School Improvement Plan for Advancing Academic Achievement, they have no clear authority to make decisions in the school. In fact, district administrators repeatedly commented that the probation managers were not co-principals and did not have decisionmaking authority, nor did they appear to have the ability to sanction either principals or other personnel.

Comments about their lack of authority and the confusion in their role were commonplace in our interviews with probation managers.

While support providers may not have had clear lines of administrative authority in the schools, they did, of course, have access to other kinds of authority - primarily that which comes with professional expertise. To the extent that partners were able to convince their schools - including the teachers - that they brought a needed 
form of expertise, they were able to gain professional authority. The policy's reliance on the professional authority of support providers increases the importance of selection - both at the district level, where partners are approved, and at the school level, where they are actually chosen.

Evidence of effectiveness, on which basis selection should be made, is scarce, however. Moreover, as stated above, a school's choice of partner appeared to be made largely on the basis of who was known to schools rather than through a careful consideration of the approach or philosophy of the partner. Furthermore, to be selected, external partners may have over-promised what they could offer. Failure to follow through on these promises then decreased the school's trust in the partner's ability to do what it claimed and, thus, decreased the partner's authority. A more serious threat to professional authority, however, derived from the quality of professional development. Complaints about the usefulness of the staff development provided through the external partners were commonplace in our school-level interviews.

Probation managers also faced the need to establish professional authority if they were to gain the ear of the principal. Those who had successes in schools that were somewhat similar to their assigned probation schools had better standing in this regard than those whose contexts were very different from that faced by their principal mentee.

\section{Power}

Power consists both of the resources committed to the policy and of the structure of incentives that surround the policy. Again, we find several indicators of the power behind probation, in general, and the provision of support, in particular. With respect to incentives, the fact that probation schools, in theory, face more severe consequences should their aggregate achievement not improve would seem to provide a powerful incentive for them to attend to and put to use the assistance they receive from whatever source. However, our case study data - and indeed the interviews of district officials indicated that few personnel in these schools were motivated by the threat of reconstitution or other sanctions (Bennett, 2001; Finnigan \& Gross, 2001). Few believed that the school would be closed down or reconstituted; indeed district officials declared early on that they would not reconstitute elementary schools. We should note that this situation may be changing as some schools linger on probation indefinitely.

For the threat of sanctions to have an impact on assistance, school personnel must see a direct link between that assistance and getting off probation. This brings us back to the strength of the professional authority both partners and probation managers command. ${ }^{32}$ To the

\footnotetext{
${ }^{32}$ Here the line between authority and power becomes somewhat blurred. We mentioned in the previous section that probation managers lacked not only general decision-making authority, but also the ability (or power) to sanction principals or school staff.
} 
extent that this authority was weak or that teachers simply did not make the link (or believed that even with assistance their school would not be able to succeed), other incentives to participate in professional development would have been particularly valuable. We saw little evidence of such additional incentives. ${ }^{33}$

Perhaps the most important aspect of power in this policy, however, is simply the very substantial resources put into it. Yet, despite this large financial commitment, the assistance provided was of very limited intensity. If Supovitz and Turner (2000) are correct, it takes from 80 to 160 hours of professional development in a content area to see significant changes in practice. However, external partners spent approximately two days per week in a school and worked with individual teachers only a few times a year. In addition, workshops were generally half-day to full-day affairs. In some cases, those who attended the workshops were charged with disseminating the knowledge to others in the school; yet by all accounts, workshop attendees had a very limited understanding of the content themselves. This made it difficult for them to disseminate it even under the best of circumstances - but often the school provided little structural support for that dissemination either. External partner consultants may have tried to

\footnotetext{
${ }^{33}$ One exception was the offering of schoolbased professional development courses for college credit. The fact that teachers would be awarded credit increased their motivation to participate.
}

assist, but were generally in the schools too little time themselves. Furthermore, the workshops the external partners provided were usually unconnected, did not link to classroom interaction, and did not involve the depth that the literature on professional development suggests is necessary for professional learning.

Overall, we tend to agree with prior researchers who argue that external providers simply cannot provide the intensity of professional development needed to change classroom practice within the current resource constraints. We did not see much indication of external partners pushing teachers or administrators to participate in deeper forms of professional development to supplement their learning. Success for All and the Center for School Improvement may be exceptions to this pattern. Both sponsored intensive and extensive professional development in literacy for the individuals who then became the literacy coordinators for their schools and who provided on-theground curriculum development, professional learning, and follow-up in the area of literacy. But these were the exceptions, and even in these cases, the training for most teachers in the schools was quite limited.

Our main conclusion, then, is that the support provided to schools is too fragmentary and weak to have the deep effect needed to change instruction, though it may improve various aspects of the instructional environment. The observed weaknesses appear attributable, in part, to implementation issues and, in part, to design. 


\section{Implications}

Several implications for strengthening CPS's support policy emerge from this analysis. Here we suggest seven:

1. Constrain the market choice, both with respect to direction and in terms of quality. We believe the provision of assistance would be improved if the number of partners were limited to a handful of proven groups that were required to offer or support a coherent and comprehensive instructional program at least in the area of literacy. In this more constrained market approach, the district could better ensure both quality and appropriate variation and flexibility, assisting low-capacity schools to make more useful choices.

2. Clarify roles of support providers. The existence of multiple partners and providers almost guarantees fragmentation at the school level. We suggest that the roles of probation managers, regional education office staff, and Office of Accountability facilitators be consolidated into a single and clear line of authority in the schools and that this authority work closely with the external partner to help the school develop and implement a coherent instructional program.

\section{Develop opportunities for} learning/sharing among partners and probation managers. We strongly urge the district to design professional development for these support providers and opportunities for them to reflect collectively on their work, its effects, and resulting lessons.

4. Discourage schools from developing multiple and fragmented partnerships by giving the external partner the authority to coordinate assistance from all external sources while the school is on probation.

5. Stimulate the development of indepth, content-based professional development. An example of such staff development might be the twoweek session on reading instruction for Targeted Assistance Program teachers held in the fall of 2000. Despite the implementation problems of short notice and inconsistency with some literacy programs, this effort to foster deeper content and pedagogical content knowledge in literacy was an important step and should be pursued further.

6. Connect assistance to the standards, not just the test. We observed a real problem of teaching to the test in several of our case study schools, a problem that is exacerbated by the lack of attention to the standards and the reliance on a single indicator for both student promotion and school probation. As long as the ITBS is the sole indicator and everything rides on it, it will become the de facto standards of the district. 
7. Promote better use of data in schools by fostering the development and implementation of multiple diagnostic tools such as running records, periodic curriculum-based assessments, and examination of more extensive examples of student work.

\section{Conclusion}

The emphasis on providing lowperforming schools regular, long-term assistance to improve is a hallmark of the CPS school accountability system, one that we applaud as an example to other jurisdictions. However, our data suggest that in the lowest performing schools, current assistance efforts are simply not strong enough to overcome the deep problems in educator and organizational capacity necessary to fundamentally improve instruction. We encourage the district to revisit the design of the system to address the problems outlined in this report. While many of our recommendations do not require additional resources, others clearly do. In particular, the intensity of professional development opportunities afforded to teachers must be enhanced if the policy is to have its desired effect. As Cohen and Ball (1999) point out, teachers are the mediators of all instructional interventions. Their capacity and motivation are critical. 


\section{References}

Argyris, C., \& Schon, D. A. (1978).

Organizational learning: A theory of action perspective. Reading, MA: Addison Wesley.

Axelrod, R., \& Cohen, M. D. (1999). Harnessing complexity: Organizational implications of a scientific frontier. New York: The Free Press.

Bennett, A. (2001, April). The history, politics, and theory of action of the Chicago probation policy. Paper presented at the annual meeting of the American Educational Research Association, Seattle, WA.

Berman, P., \& McLaughlin, M. (1978). Federal programs supporting educational change, volume VII: Factors affecting implementation and continuation. Santa Monica, CA: RAND.

Chicago Public Schools. (1999). Guidelines for external partners, 1999-2000. Chicago: Author.

Chicago Public Schools. (2000a). Probation support system. Chicago: Author.

Chicago Public Schools (2000b). School probation policy. Chicago: Author.

Chimerine, C. B., Haslam, M. B., \& Laguarda, K. G. (1994). Third-year evaluation of the nine site program improvement initiative. Washington, DC: Policy Studies Associates.
Cohen, D. K., \& Ball, D. L. (1999).

Instruction, capacity, and improvement (CPRE Research Report Series No. RR43). Philadelphia: Consortium for Policy Research in Education, University of Pennsylvania.

Cohen, D. K., \& Hill, H. C. (1998). Instructional policy and classroom performance: The mathematics reform in California (CPRE Research Report Series No. RR-39). Philadelphia: Consortium for Policy Research in Education, University of Pennsylvania.

Corcoran, T. (1995). Helping teachers teach well: Transforming professional development (CPRE Policy Brief Series No. RB-16). New Brunswick, NJ: Consortium for Policy Research in Education, Rutgers University.

Corcoran, T., Wang, A., \& Foley, E. (1999, April). What kinds of professional development build capacity better?An analysis of the impact of professional development on teaching practice in the School District of Philadelphia. Paper presented at the annual meeting of the American Educational Research Association, Montreal, Canada.

Cox, P. (1983). Complementary roles in successful change. Educational Leadership, 41(3), 10-13.

Darling-Hammond, L. (1996). Restructuring schools for high performance. In S. H. Fuhrman \& J. A. O'Day (Eds.), Rewards and reform: Creating educational incentives that work (pp. 144-192). San Francisco: Jossey-Bass Publishers. 
David, J. L., Kannapel, P. J., \& McDiarmid, P. (2000). The influence of distinguished educators on school improvement: A study of Kentucky's school intervention program. Lexington, KY: Partnership for Kentucky's Schools.

Edmonds, R. (1979). Effective schools for the urban poor. Educational Leadership, $37,15-27$.

Elmore, R. F. (1987). Reform and the culture of authority in schools. Educational Administration Quarterly, 23(4), 60-78.

Fennema, E., \& Carpenter, T. (1992). Cognitively guided instruction. NCRMSE research review: The teaching and learning of mathematics, 1(2), 5-9.

Finnigan, K., \& Gross, B. (2001, April). Teacher motivation and the Chicago probation policy. Paper presented at the annual meeting of the American Educational Research Association, Seattle, WA.

Fullan, M. (1991). The new meaning of educational change, second edition. New York: Teachers College Press.

Goertz, M. E., Floden, R., \& O'Day, J. A. (1995). Studies of education reform: Systemic reform, volume 1: Findings and conclusions. New Brunswick, NJ: Consortium for Policy Research in Education, Rutgers University.

Hatch, T. (1998). The differences in theory that matter in the practice of school improvement. American Educational Research Journal, 35(1), 3-31.
Hawley, W. D., \& Valli, L. (1998). Guide to the National Partnership for Excellence and Accountability in Teaching (NPEAT). Washington, DC: ERIC Clearinghouse on Teaching and Teacher Education, American Association of Colleges for Teacher Education.

Huberman, M. (1995). Professional careers and professional development: Some intersections. In T. R. Guskey \& M. Huberman (Eds.), Professional development in education: New paradigms and practices (pp. 193-224). New York: Teachers College Press.

Kennedy, M. M. (1998). Education reform and subject-matter knowledge. Journal of Research in Science Teaching, 35(3), 249-263.

Levine, D., \& Lezotte, L. (1990). Unusually effective schools: A review and analysis of research and practice. Madison, WI: National Center for Effective Schools Research and Development.

Little, J. W. (1993). Teachers' professional development in a climate of educational reform. Educational Evaluation and Policy Analysis, 15(2), 129151.

McLaughlin, M. (1987). Learning from experience: Lessons from policy implementation. Educational Evaluation and Policy Analysis, 9(2), 171-178.

McLaughlin, M., \& Talbert, J. (1993). Contexts that matter for teaching and learning. Stanford, CA: Center for Research on the Context of Teaching, Stanford University. 
Mohrman, S. A., \& Lawler, E. E. (1996). Motivation for school reform. In S. H. Fuhrman \& J. A. O'Day (Eds.), Rewards and reform: Creating educational incentives that work (pp. 115-143). San Francisco: Jossey-Bass Publishers.

Newmann, F. M., \& Wehlage, G. G. (1995). Successful school restructuring: A report to the public and educators by the Center on Organization and Restructuring of Schools. Madison, WI: Center on Organization and Restructuring of Schools, University of WisconsinMadison.

Newmann, F., King, M. B., \& Youngs, P. (2000, April). Professional development that addresses school capacity: Lessons from urban elementary schools. Paper presented at the annual meeting of the American Educational Research Association, New Orleans, LA.

O'Day, J. A., Goertz, M. E., \& Floden, R. (1995). Building capacity for education reform (CPRE Policy Brief Series No. RB18). New Brunswick, NJ: Consortium for Policy Research in Education, Rutgers University.

Porter, A., Floden, R., Freeman, D., Schmidt, W., \& Schwille, J. (1988). Content determinants in elementary school mathematics. In D. Grouws \& T. Cooney (Eds.), Perspectives on research on effective mathematics teaching, volume 1 . Reston, VA: National Council of Teachers of Mathematics.

Purkey, S., \& Smith, M. S. (1983). Effective schools: A review. Elementary School Journal, 83(4), 427-452.
Roderick, M., Bryk, A. S., Jacob, B. A., and Easton, J. Q. (1999). Ending social promotion: Results from the first two years. Chicago: Consortium on Chicago School Research.

Shulman, L. S. (1986). Those who understand: Knowledge growth in teaching. Educational Researcher, 15(2), 414.

Shulman, L. S. (1987). Knowledge and teaching: Foundations of the new reform. Harvard Educational Review, 57(1), 1-22.

Smylie, M. A., Bilcer, D. K., Greenberg, R. C., \& Harris, R. L. (1998, April). Urban teacher professional development: A portrait of practice from Chicago. Paper presented at the annual meeting of the American Educational Research Association, San Diego, CA.

Spillane, J. (2000). Cognition and policy implementation: District policymakers and the reform of mathematics education. Cognition and Instruction, 18(2), 141-179.

Supovitz, J. A., \& Turner, H. (2000). The influence of standards-based reform on classroom practices and culture. Journal of Research in Science Teaching, 37(9), 963980.

Sunderman, G., \& Nardini, G. (1999, April). Institutional constraints on implementing school reform: Lessons from Chicago. Paper presented at the annual meeting of the American Educational Research Association, Montreal, Canada. 
Weatherly, R., \& Lipsky, M. (1977).

Street-level bureaucrats and

institutional innovation: Implementing

special education reform. Harvard

Educational Review, 47(2), 171-197. 


\section{Appendix A. Description of External Partners Participating in Study}

\begin{tabular}{|c|c|c|}
\hline Name of Organization & Type of Support & $\begin{array}{l}\text { Number of } \\
\text { Schools } \\
\text { Served } \\
\text { During Study }\end{array}$ \\
\hline Accountability Direct Instruction Model & Instruction-Direct Instruction K-6 & 4 \\
\hline $\begin{array}{l}\text { Achieving High Standards Project, } \\
\text { University of Illinois-Chicago }\end{array}$ & Instruction-Four Blocks of Literacy & 3 \\
\hline Brad Frieswyk Group & Instruction-Direct Instruction K-8 & 6* \\
\hline $\begin{array}{l}\text { Center for School Improvement, } \\
\text { University of Chicago }\end{array}$ & $\begin{array}{l}\text { Instruction-Literacy, STEP Assessments } \\
\text { Organization-Academic and Social } \\
\text { Supports System, Principal Network, } \\
\text { Grand Rounds Review }\end{array}$ & 2 \\
\hline Center for Urban Education, DePaul University & Instruction and Organization & 33 \\
\hline Community for Learning, Temple University & $\begin{array}{l}\text { Instruction-Adaptive Learning Environment } \\
\text { Organization-Degree of Implementation } \\
\text { Report }\end{array}$ & 10 \\
\hline $\begin{array}{l}\text { Interactive Teaching and Learning, } \\
\text { Northeastern Illinois University }\end{array}$ & $\begin{array}{l}\text { Instruction } \\
\text { Organization-Needs Assessment, } \\
\text { Planning Assistance }\end{array}$ & 8 \\
\hline National School Services/I Had a Dream, Inc. & Instruction & 5 \\
\hline $\begin{array}{l}\text { School Achievement Structure, } \\
\text { DePaul University }\end{array}$ & $\begin{array}{l}\text { Organization-Ten Structured Routines, } \\
\text { Self-study }\end{array}$ & 12 \\
\hline $\begin{array}{l}\text { Small Schools Workshop, } \\
\text { University of Illinois-Chicago }\end{array}$ & Organization-Small Schools within Schools & 3 \\
\hline Valina Miller Group & Instruction and Organization & 3 \\
\hline
\end{tabular}

* This partner was subcontracted by School Achievement Structure to work in four probation schools. 